\title{
Securing the Harmony between the High and the Low: Power Animals and Symbols of Political Authority in Ancient Chinese Jades and Bronzes
}

\author{
$\Delta \cdot \Delta \cdot \Delta$ \\ RUI OLIVEIRA LOPES
}

\section{INTRODUCTION}

ONE OF THE ISSUES THAT HAS GIVEN RISE TO LENGTHY DISCUSSIONS AMONG ART HISTORIANS is that of the iconographic significance of Chinese Neolithic jade objects and the symbolic value the decorations on bronze vessels might have had during the Shang (c. 1600-1045 B.c.) and Zhou (1045-256 B.c.) dynasties. Some historians propose that the representations of real and imaginary animals that often decorated bronze vessels bore no specific meaning. The basis of their argument is that there is no reference to them among the oracle bones of the Shang dynasty or any other contemporaneous written source. ${ }^{1}$ They therefore suggest that these were simply decorative elements that had undergone a renovation of style in line with an updating of past ornamental designs, or through stylistic influence resulting from contact with other peoples from western and southern China (Bagley 1993; Loehr 1953). Others, basing their arguments on the Chinese Classics and other documents of the Eastern Zhou and Han periods, perceive in the jades and bronzes representations of celestial beings who played key roles in communicating with ancestral spirits (Allan 1991, 1993; Chang 1981; Kesner 1991). The transfer of knowledge that determined the continuity of funerary practices, ritual procedures, artistic techniques, and the transmission of the meanings of iconographic representations was certainly subject to some change, but would have been kept in the collective memory and passed on from generation to generation until it was recorded in the most important documents regarding the institutions of Chinese culture.

The fact that there are no written references to the meanings of certain types of jade objects and the iconography that decorates bronze vessels prevents us from immediately grasping their ritual, religious, and political values. It is nevertheless undeniable that the material culture that comes from archaeological sites of ancient societies does allow us to reconstitute some aspects of the importance of such objects, especially when they occur in the context of funerary rites. Furthermore, universal 
characteristics inherent to human religious behaviour are reflected in the creation of mythological narratives and, consequently, in the visual and artistic formulation of the imaginary of myths. One may assert that visual representations that utilize elements of nature that surround humankind are the first form of narrative, earlier than writing itself. It is worth noting that the oldest Chinese characters found on Neolithic ceramics, early ritual bronzes of the Shang dynasty, and (in a more developed form) on oracle bones of the late phase of the Shang period are essentially pictograms. These pictograms became increasingly stylized through time to a more abstract form.

The large number of jade objects and ritual weapons, characteristic of some Neolithic cultures in China, reveals the contours of a spirituality rooted in the structures of societal organization. Although there are no references prior to the Eastern Zhou dynasty of the meaning of some of the more abstract shapes of Neolithic objects, such as the $b i$ (flat discs with a central circular hole) and cong (prismatic tubes), other objects are shaped like or decorated with mimetic or stylized representations of birds, turtles, cicadas, and silkworms. The symbolic value of these latter designs would certainly have been related to their perceptible qualities. Curiously, shamans in the middle and late phases of the Shang dynasty used oracle bones made from animals that had been widely represented in jade during the Neolithic period.

Marking the transition between the Neolithic and the Bronze Age, the Erlitou culture (c. 1900-c. 1500 B.C.) increased its area of influence along the south bank of the Luo River, precisely in the same place that had been occupied earlier by the Yangshao (5000-3000 B.c.) and then by the Longshan (2800-2000 B.C.) cultures. $^{2}$ Archaeological evidence confirms the continuity of funerary practices and iconographic motifs between the late Neolithic and the early Bronze Age (Liu 2002). The funerary practices in many of the archaeological sites of the Neolithic and early Bronze Age, such as Erlitou and Zhengzhou, are substantially identical, from the cardinal orientation and stratification of the grave to the typology and distribution of the objects.

Bronze ritual vessels and weapons modeled upon ceramic and jade objects dating from the Neolithic have been frequently unearthed at Erlitou culture sites. Besides bronze ritual vessels, ornaments such as a bronze plaque with a turquoise inlay of a mask and a dragon-shaped scepter were also found. These were certainly symbols of the authority of a clan leader or shaman or both. Such iconographic elements based upon a symbolic ancestral language were extensively reproduced during the Shang dynasty. Shang craftsmen demonstrated astounding versatility in the decoration and artistic sophistication of bronze vessels and jade ritual objects.

The value and meaning of objects change both over time and according to the political and religious situation. As shall be seen, when political power emerged and consolidated around the figures of the sovereign and the aristocracy, objects started losing their purely spiritual value and began to reflect the authority and status of their owner through merely ornamental elements. The late phase of the Shang marked a transition from sacred rites consecrated to Heavenly sovereignty to an institutionalization of ceremonies glorifying political power. In this shift, the symbolic meaning of the objects used during the sacred rites was either entirely lost, reimagined, or gave way to new symbols and meanings that ceased to reflect the relationship between Heaven and Earth, instead mirroring the legitimacy of political authority. 


\section{BETWEEN HEAVEN AND EARTH}

Approximately 10,000 years ago, the Neolithic period in China marked the beginning of a new era brought about by the development of agriculture and animal husbandry, particularly along the banks of the Yellow River in northern and central China and the Yangzi River in southern China (Chang 1999:42-47). However, in recent decades archaeological excavations have unearthed jade objects in the shape of dragons and small clay-molded human figurines that demonstrate the existence of significantly developed social groups along the Liao River, in Liaoning Province and Inner Mongolia (Childs-Johnson 1988; Nelson 1995).

Despite the development of agriculture and several technologies connected to social restructuring, such as the manufacturing of tools and the production of ceramics to conserve the yield of crops, both fishing and hunting of a variety of animals, such as turtles, water buffalo, and some species of deer, were continued as a significant mode of subsistence. The abundance of food resources from agriculture, animal husbandry, and fishing and hunting provided ideal conditions for demographic growth and, consequently, permitted the specialization of resources focused on essential aspects of society. The development of manufacturing techniques to make stone tools and the production of ceramics are some of the most remarkable examples.

Successful agriculture depended upon observing and understanding the cyclical action of natural phenomena. Such observations were fundamental for the prosperity of social groups. Moreover, they constituted a spiritual consciousness that attributed mystic properties to elements of nature. Human vulnerability in the face of the forces of nature led to the creation of mythological systems and cosmogonies of creation associated with universal principles that established a relationship between Heaven and Earth. Earlier prestate societies identified Heaven with transcendence and inaccessibility and Earth with the mundane world. Earth's fertility depended upon the creative force of Heaven being manifested in the rain that falls from the sky and the rivers that stream between the mountains. Within the cyclical relationship between Heaven and Earth, mountains represented a way of narrowing the distance between humans and Heaven. They constituted simultaneously a means to ascend from Earth to Heaven and as a space of communion with the sacred. ${ }^{3}$

Although there are no written sources that provide us with a clear picture of the religious systems of Neolithic societies, comparing archaeological evidence of that period with the knowledge we currently have about the spirituality of the Shang (as recorded in oracle bones) strengthens the idea that human's transcendental relationship with nature preceded the Bronze Age. The human creative consciousness gave way to an imaginary of forms that emulated the integration between Heaven and Earth through symbolic representations of the cyclical actions of the cosmic order and the elements of nature. Extracted from the veins of high mountains and riverbeds that covered immense distances, jade would certainly have held symbolic value in the context of funerary practices and eventually other rites during the Neolithic.

Evidence for the production of jade objects have particularly been found at sites of the Xinglongwa (8500-7000 B.C.) and Hongshan (3400-2300 B.C.) cultures settled along the banks of the Liao River in Liaoning Province and Inner Mongolia; the Hemudu culture (5000-3400 B.C.) near Hangzhou Bay in Zhejiang Province; the Longshan culture along the Yangzi River, and the Liangzhu culture (3200-2200 B.C.) 


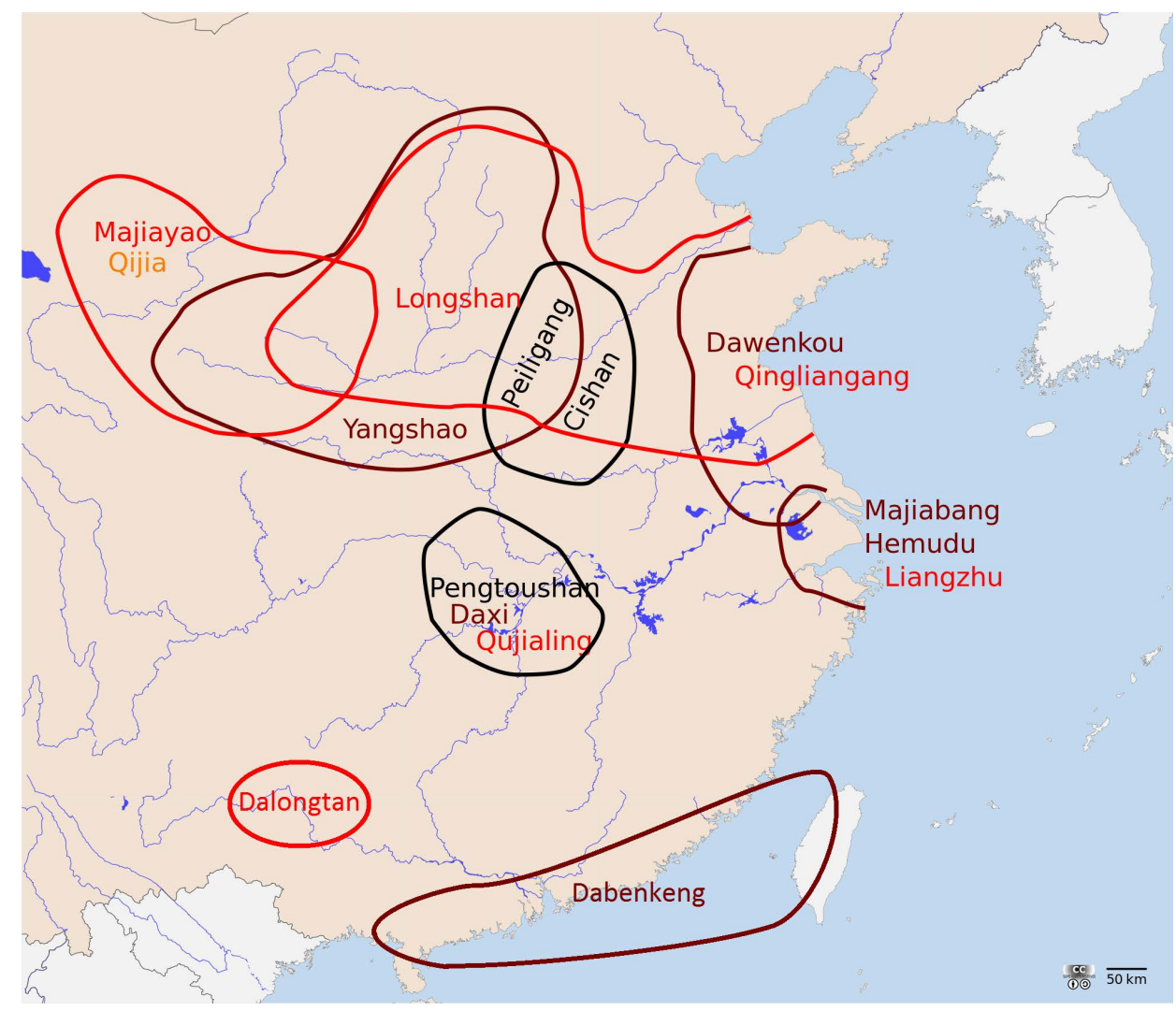

Fig. 1. Areas occupied by different Neolithic cultures of China. Source base map: Wikipedia Creative Commons.

around the region of Lake Tai in the Yangzi River Delta (Guo 1995; Lin 2000; Rawson 1992: 50-54; 2009) (Fig. 1).

The complexity and skill of the manufacturing process, and the restricted ritual and social contexts (usually burials) in which these objects were recovered, likely reflect a significant change in the organizational structure of social groups in this period. Due to jade's unique hardness and the complex manufacturing skills and technology necessary to work jade, the production of these objects implies the existence of an organized structure of labor involving a large number of specialized craftsmen with knowledge in handling specific tools for working jade. Supposedly, the majority of tools for working jade would have been made of wood and bamboo, along with sand-based abrasives that enabled the perforation and polishing of the surface of the object. Some archaeologists have proposed that an emery wheel (similar to a whetstone) might have been used; it was probably mounted on a mechanized axle in order to cut the stone, abrade the surface, and outline the profile of these objects. The friction of ropes coated with a paste of emery and quartz crystals would have been one of the cutting techniques developed by the Hongshan culture, but it was also probably used later by the Liangzhu culture (Sax et al. 2004; Sax et al. 2007) (Figs. 2, 3, and 4). 


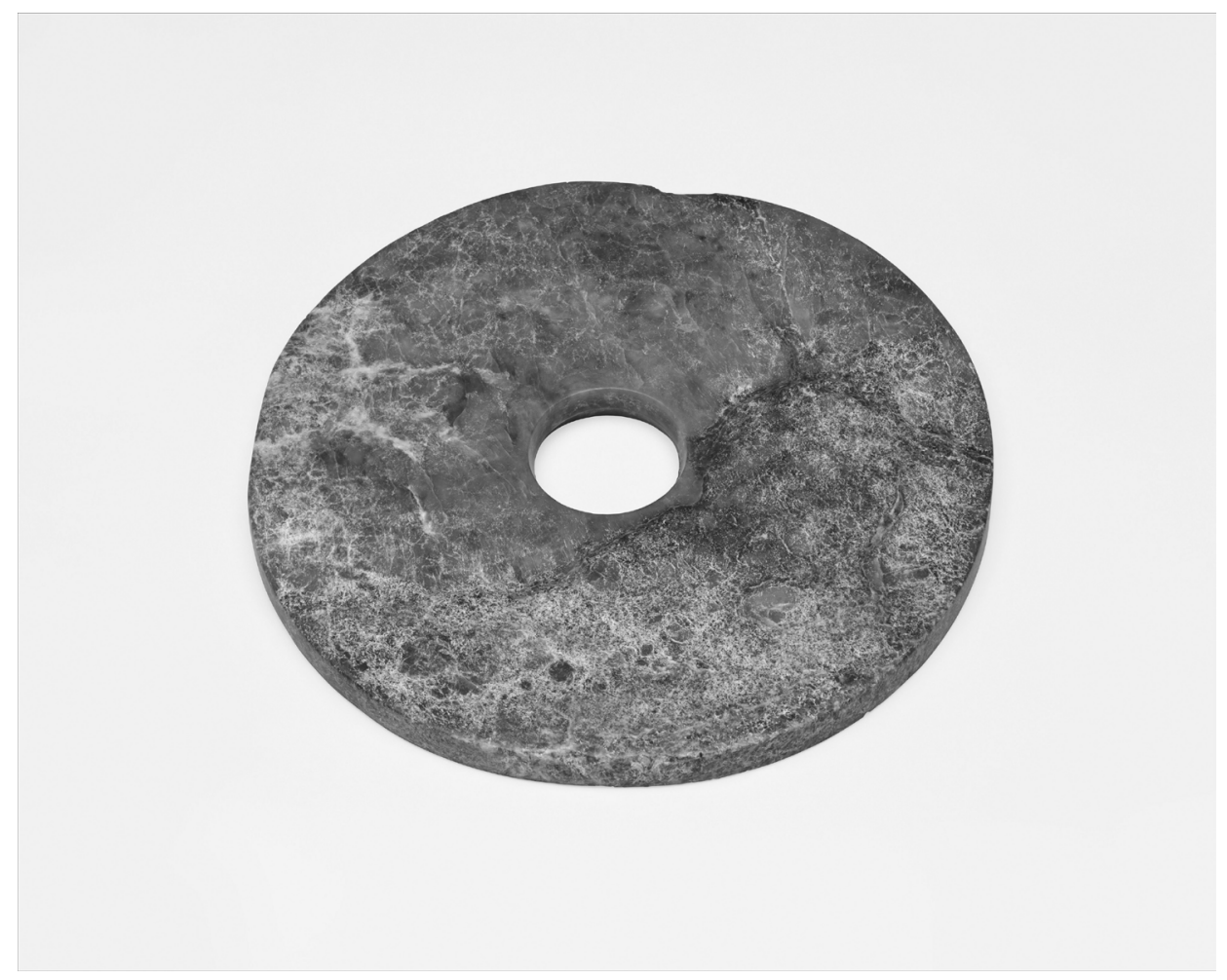

Fig. 2. Bi disc, a ritual jade object from Liangzhu culture (c. 3200-2000 B.c.). Diameter: $21.3 \mathrm{~cm}$. Source: Accession Number 1986.112, Metropolitan Museum of Art, New York, www.metmuseum.org.

The Liangzhu culture, which emerged in the aftermath of the decline of the Majiabang (5000-3200 в.с.) and Songze (5000-3200 B.c.) cultures, greatly developed these jade-working techniques. The well-known cong (prismatic tubes) as well as countless bi (jade discs), have been commonly found in Liangzhu sites, many of them decorated with figures and masks in high relief (Li 1993). Long perforations in the cong tubes and bi discs would have been made with bamboo drilling tools and a mixture of water and quartz, since these objects usually present elliptic grooves along the perforation. Due to the enormous pressure exerted, the perforations were made alternately in either side, resulting in a bulge more or less halfway across the opening. Tools made of flint and shark teeth have been discovered alongside jade objects unearthed in archaeological excavations; they might have been used to decorate and inscribe clan insignia on the jade's surface. The stylistic features and the formal design of the jade objects, especially of the cultures that over time settled along the banks and delta of the Yangzi River, would suggest that there was a continuous transmission of knowledge through space and time, rather than a well-defined cultural boundary between the different cultures.

The Xinglongwa culture is one of the oldest and most paradigmatic cultures of the Neolithic; its area of influence covered the region of Chifeng around 8000 B.C. (Chang 1999: 49; Liu and Chen 2002; Tang et al. 2007). Besides attesting to an urban 


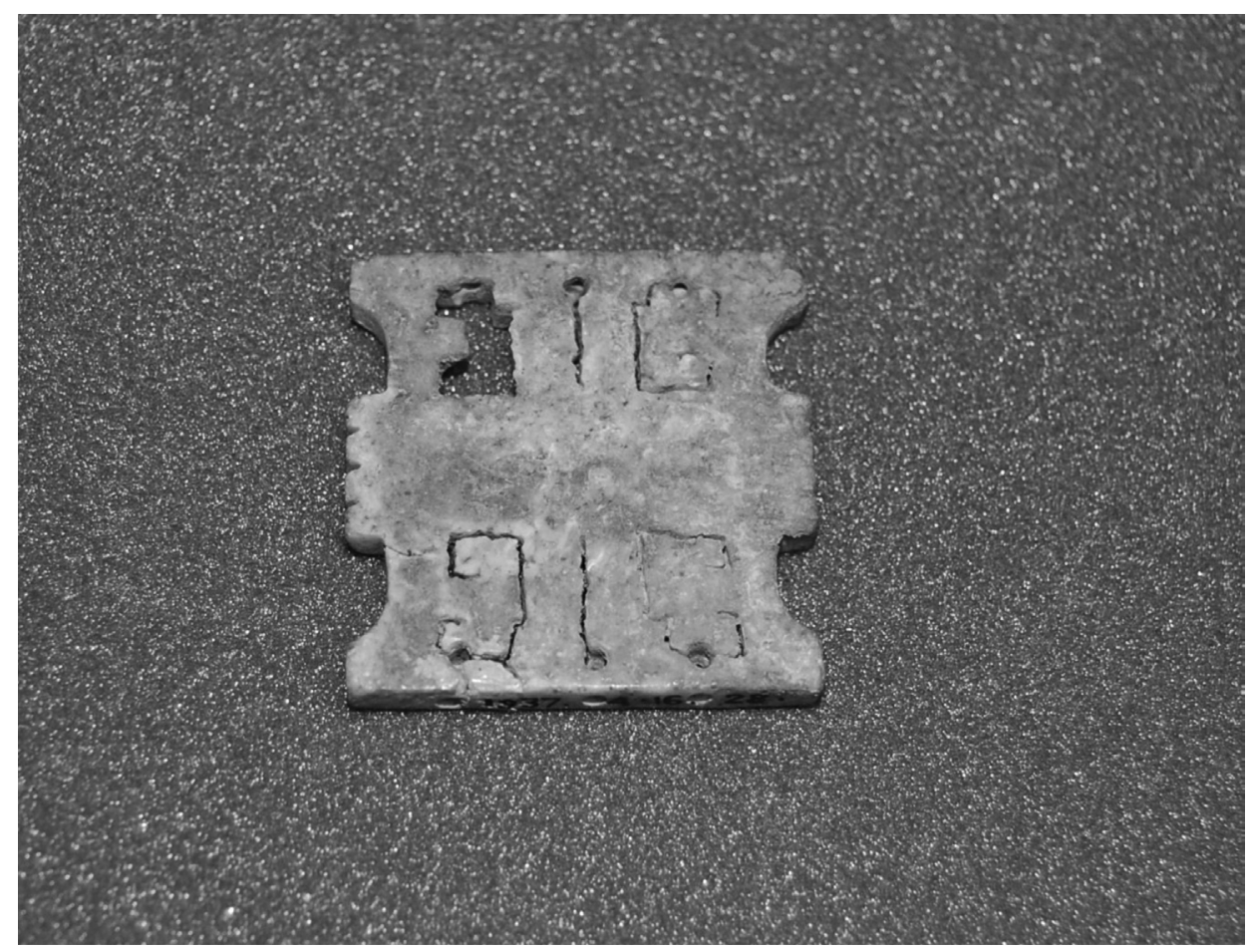

Fig. 3. Jade pendant, Eastern Zhou dynasty (770-221 в.c.). Dimensions: $3.81 \times 3.80 \mathrm{~cm}$. Source: Museum Number 1937,0416.28, British Museum.

expansion in three phases, archaeological surveys in the area have revealed the existence of funerary rites involving animal sacrifice and the use of several types of funerary jade objects. These included penannular-shaped ornamental jades, arc-shaped implements, jade beads, and other objects in the form of ordinary agricultural tools such as shovels, adzes, axes, and chisels. Some of the arc-shaped implements are perforated at least at one of the ends, so they might have been used as pendants. The penannular-shaped jades have usually been found in pairs close to the head of the tomb's occupant, suggesting that they may have been used as earrings. Just as tombs included sacrificed domesticated animals such as pigs, and wild animals that were part of the regular diet, like different types of deer and pheasants, they also symbolically included agriculture-related utensils. Some jade objects shaped like ordinary agricultural tools have been found in tombs of the Xinglongwa culture-symbols of agriculture's importance in the context of funerary rites. In this context these seemingly utilitarian jade objects represented offerings for a prosperous and plentiful afterlife, or were perhaps consecrated to the spirits who controlled the elements of nature and looked after the welfare of humans.

Ornamental objects are also very common in the archaeological sites of the Hongshan culture and other Neolithic cultures in northeastern China. This suggests that the Xinglongwa culture predated the origin of later cultures that developed in the same geographic area (Guo $1995: 21-24)$. 


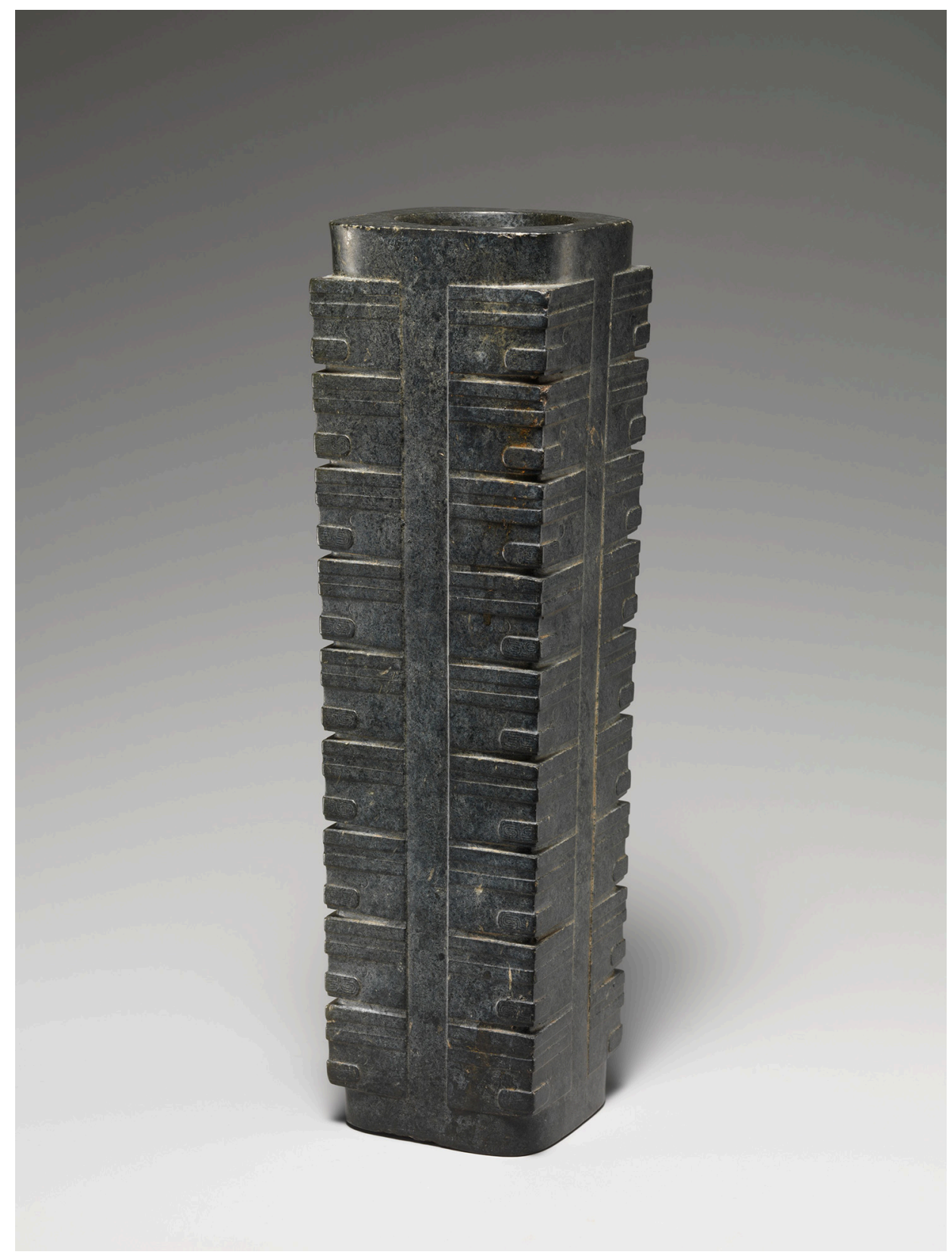

Fig. 4. Ritual object (cong), Liangzhu culture (c. 3200-2000 B.c.), c. 2400. Dimensions: h. 25.4 cm; w. 7 cm. Source: Accession Number 2004.52, Metropolitan Museum of Art, New York, www. metmuseum.org. 
The Hongshan culture is particularly known for the technical quality of its jade objects, its very diverse representations of realistic and mythological animals, and a spiritual imaginary arising from the interaction between humans and the natural world. In Niuheliang, presumed the largest settlement of the Hongshan culture, a tomb containing a human skeleton, buried with nine jade pieces in a stone chamber, was unearthed. Among these artifacts was a cloud-shaped pendant, placed on the chest, and a C-shaped piece and two large bi discs placed on the head of the entombed individual. Three ring-shaped objects, one jade bead, and an object in the form of a bird were discovered on the lower part of the individual. Other, more modest tombs found in the area each contained between one and five simpler smaller objects. Only one of the smaller tombs contained a ring-shaped dragon; it had a small perforation so it could be used as a pendant.

The majority of jade objects of the Hongshan culture that have been unearthed in an archaeological context have been found in Niuheliang, Sanguandianzi, and Dongshanzui. Among more common objects such as beads, annular and semi-annular (huang) pendants, and bi discs, objects shaped like animals such as ring-shaped dragons, tigers, pigs, turtles, birds, and cicadas have been found. The more common artifacts are thought to be ornamental implements for hair and clothing. Some relatively large objects in the shape of a truncated cone with two openings at either extremity, one larger than the other, are thought to have been used to hold hair, since they were found placed behind the head. Amongst all the animal-shaped objects, birds, turtles, dragons, cicadas, and silkworms appear most frequently. According to the natural qualities of each animal depicted, such artifacts would eventually have acquired specific significance in the context of funerary rites.

During the Shang dynasty, sacred rites were consecrated to the deity, Shang Di, which literally means High Sovereign. Shang Di was perceived as synonymous with Heaven. According to the inscriptions on oracle bones used in Shang rituals, where the earliest references to the deity are found, Shang Di was the sovereign of the entire natural world and the ancestral spirits who, in the deity's name, determined the destiny of humans. Shang Di controlled all forces of nature, so provided the rains needed for growing crops and minimized river floods so as to prevent total devastation. The cosmogonies of the natural order, which are reflected in the sacralization of Heaven, mountains, rivers, and other elements of nature that interfere with the order of humanity, refer to archetypes that are universal and common to different anthropological structures. Cultural materials from various civilizations in Europe, Africa, and South America provide evidence of worship of the heavenly dome or firmament, and refer to a Supreme God as sovereign over all of nature. Creation flood myths, which often highlight both the destruction and regeneration of humanity, are revealed in the story of Nuwa and Fuxi in the Chinese tradition, in the biblical description of Noah's Ark, and in Vedic narratives that describe the way Vishnu created all things of the world after the destruction caused by the Cosmic Ocean. The creation of man from clay is described in Babylonian epics, Egyptian and Mayan mythologies, and Chinese popular tradition with the tale of Nuwa's creation of the first human beings from mud and clay. Such sacred systems are a feature of the human spiritual consciousness. Even before the development of writing, the human spiritual imaginary created a set of rituals and symbolic language to manifest religious behavior.

Just as mountains, because of their verticality and the inaccessibility of their summits, are believed inhabited by the ancestral spirits and constitute a place for 
communing with Heaven, birds, because of their wings, stand for an axiological connection with Heaven (Bachelard 1943). The flight of the bird covers the distance between Heaven and Earth, connects the celestial space with the space of humanity, and may eventually stand for the spiritual journey of the deceased or even whoever presides over the burial ritual. For example, on oracle bones dated from the final stage of the Shang dynasty, the phoenix is described as the messenger of Heaven; it establishes the connection between Heaven and Earth, between the celestial world and the world of humanity (Chang 1981).

The turtle has the ability to transit between the Earth and the Great Ocean, being able, in the imaginary of early societies, to stand for the spiritual journey between the world of humans and the underworld. It is also important to note that a significant number of oracle "bones" are actually made of turtle plastron, the underside part of a turtle's shell. The use of plastron for oracular purposes demonstrates that the turtle was inextricably associated with communication with ancestral spirits during the Shang dynasty; such an association might have originated in Neolithic rituals. Oracle "bone" fragments made of both turtle shell and plastron have been found in several archaeological sites from the Neolithic. In some cases, they reveal traces of red pigment. Similarly, many archaeological finds from the Dawenkou culture (4300-2200 B.C.) include turtle shells, some incised on the surface with marks reminiscent of inscriptions on Shang dynasty oracle bones. Many of these fragments are perforated at the edges, probably to join the shell to the plastron. In one Neolithic tomb in Lingjiatan in present-day Hanshan, Anhui Province, dated from c. 2500 B.c., a jade turtle composed of two parts (shell and plastron) with the same type of perforations found on the turtle fragments from the sites of the Dawenkou culture (Liu 2004:64-67) was found. A rectangular jade plaque placed between the shell and plastron has an elaborate diagram engraved on one of its surfaces. The diagram is very similar to what later would be defined as the Eight Trigrams, which were used in a divination method in ancient China and later periods. Although it is not certain that this jade object or turtle shells were ever used in the Neolithic as a system of divination or communication with Heaven, there seems no doubt that the turtle bore that function in the context of funerary practices. The fact that, during the later Shang dynasty, turtle oracle bones (along with the bones of other animals) were used in rituals of divination and communication with Heaven suggests continuity of practice with Neolithic rituals.

The dragon is probably one of the most important mythical animals and is also commonly represented in several cultures as a major iconography symbol. Dragons may have been derived from exaggerated depictions of snakes and are archetypal images associated with water and the transcendent world. The dragon is often a hybrid of many animals, with scales similar to those of fish and serpents, wings like birds, and horns similar to deer or water buffalo. By combining the qualities of these animals, the dragon is able to move between Heaven, Earth, and the Cosmic Ocean. Because of its terrifying appearance, the dragon is also thought to protect the gates of the underworld from evil spirits.

Also frequently placed in tombs throughout the Neolithic, jade cicadas and silkworms are widely connected to the cycles of life and death, and with the myths of death and rebirth. Both animals represent a process of metamorphosis similar to that which humans undergo throughout life. In this context, death is a process of physical transformation and transition to a new form of life or existence, and funerary 


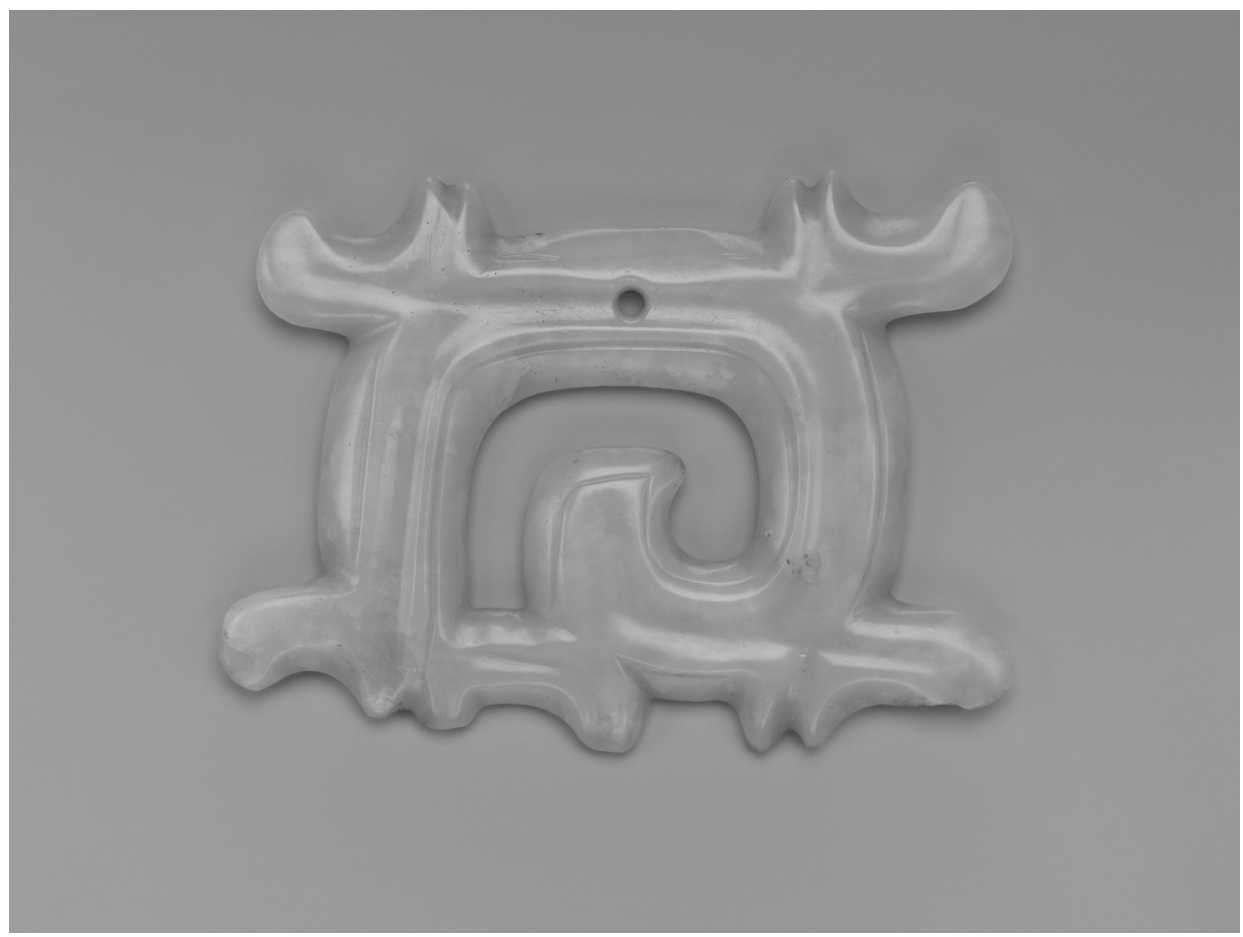

Fig. 5. Plaque in the shape of a squarish loop with projections (Gouyun pei), Hongshan culture (c. 3500-2000 B.c.). Dimensions: h. 7.3 cm; w. 9.8 cm. Source: Accession Number: 2009.176, Metropolitan Museum of Art, New York, www.metmuseum.org.

ceremonies consist of a celebration and a ritual of passage. After hatching from eggs, cicadas burrow underground to live for several years, feeding on root sap. When they reach maturity, they climb on to a tree where they undergo metamorphosis and are then ready to mate, dying after laying their eggs. Although they do not live underground, silkworms undergo a similar process of metamorphosis inside a cocoon, from which they emerge as moths. In China, the production of silk textiles dates back at least to c. 3500 B.C., during the Neolithic, which means that there was, almost certainly, extensive knowledge of the life cycle not only of cicadas and silkworms, but also of many other animals that were pivotal in meeting the primordial needs of society in terms of food resources, material production, and ritual practices.

Scholars have seen jade objects as representations of cosmological symbols such as Heaven, Earth, wind, and clouds (Childs-Johnson 1988). Apart from the ring-shaped dragon, one of the most distinctive objects from the Hongshan culture is a pendant in the form of a cloud. These pendants usually have beveled edges (Fig. 5). Some have perforations in the center in the shape of a face. Clouds are naturally correlated with Heaven and the manifestation of natural forces; they symbolize prosperity and abundance because they provide the rain much needed for crops. The fact that their shape was used as pendants and found in tombs belonging to elite individuals indicates that there was a hierarchical social structure ruled by one or more sovereign-shamans who held both spiritual and political authority. 
Because of their unbroken circular shape, $b i$ discs have been interpreted in later sources as a symbol of Heaven or the heavenly dome, and possibly the cyclical action of the natural world. For example, the Rites of the Zhou (Zhou Li 周礼) lists bi discs at the top of the list of most important utensils and states that they were used in sacrifices to Heaven (Teng 2000). Apart from the more common forms of discs with no decoration, there are also objects from the Hongshan culture with two or three overlapping perforations, with a ring-shaped profile, possibly used as pendants. However, the true meaning of these objects is as yet unknown.

$\mathrm{Bi}$ discs and cong tubes constitute the most significant and paradigmatic jade ritual objects used in funerary practices in the Yangzi River Delta region. Bi discs have been discovered in large numbers in sites of the Liangzhu culture. The large size of many of the $b i$ discs renders them unfit to have been used as ornaments for ritual attire. They were nevertheless usually placed underneath the corpse and on the top of the chest and stomach, while smaller ones were placed around the body. Cong are prismatic objects on the outside, often decorated with geometric designs or masks on each of the four corners. The interior is a hollow cylinder. As with bi discs, some scholars have suggested that the circular interior of the cong symbolizes Heaven, while its squarish exterior may represent Earth because of the four cardinal directions (Allan 1991, 1993). However, this interpretation is based on the meanings these objects held during the Zhou dynasty, which may differ from the original meaning attributed to them in the Liangzhu culture. While we remain ignorant of the real meaning of these objects, both bi discs and cong tubes clearly played a central role in Liangzhu rituals.

Techniques for cutting, perforating, and abrading the surface of jade progressed significantly during the Liangzhu culture, enabling a greater and more diversified production of ritual jade objects. Apart from perfecting the shapes, this resulted in the surfaces of $b i$ discs and the corners of cong tubes becoming lavishly ornamented with one or more anthropomorphic masks in relief (Fig. 6). A common iconographic element of Liangzhu jade objects, the animal mask motif was essentially designed with two bulging eyes aligned above a nose and mouth, although there are also variations that combine the anthropomorphic mask with a man. The man, wearing a crown of feathers and with arms open, is represented over the mask's eyes, apparently mounted on the animal.

This interaction between man and animal corresponds to an iconographic element that appears quite frequently during the Shang and Zhou dynasties ( $\mathrm{Li}$ 1993). The Palace Museum in Beijing has in its collection a fragment of silk found in a tomb from the State of Chu (Warring States Period) that contains a painting with the depiction of a man mounted on a dragon. A jade object depicting a man mounted on an animal was also found in Luoyang, the capital of the Eastern Zhou dynasty. In fact, this object seen from the front recalls the depictions of man atop an animal ordinarily seen in Liangzhu objects. Furthermore, the configuration of the eyes of the masks or animals is very similar to the ones we see in many of the ring-shaped dragons of the Hongshan culture (Fig. 7). The man and animal motif is an archetypal image of the animal as celestial vehicle that provides ordinary man with the ability to rise to Heaven and communicate with ancestral spirits.

The technological developments that enabled large production of jade objects, as well as relief decorations of their surfaces, certainly derived from greater political cohesion and contiguity to rising political states in surrounding areas (Liu and Chen 2002). Thus, besides the bi and the cong objects associated with status and political 


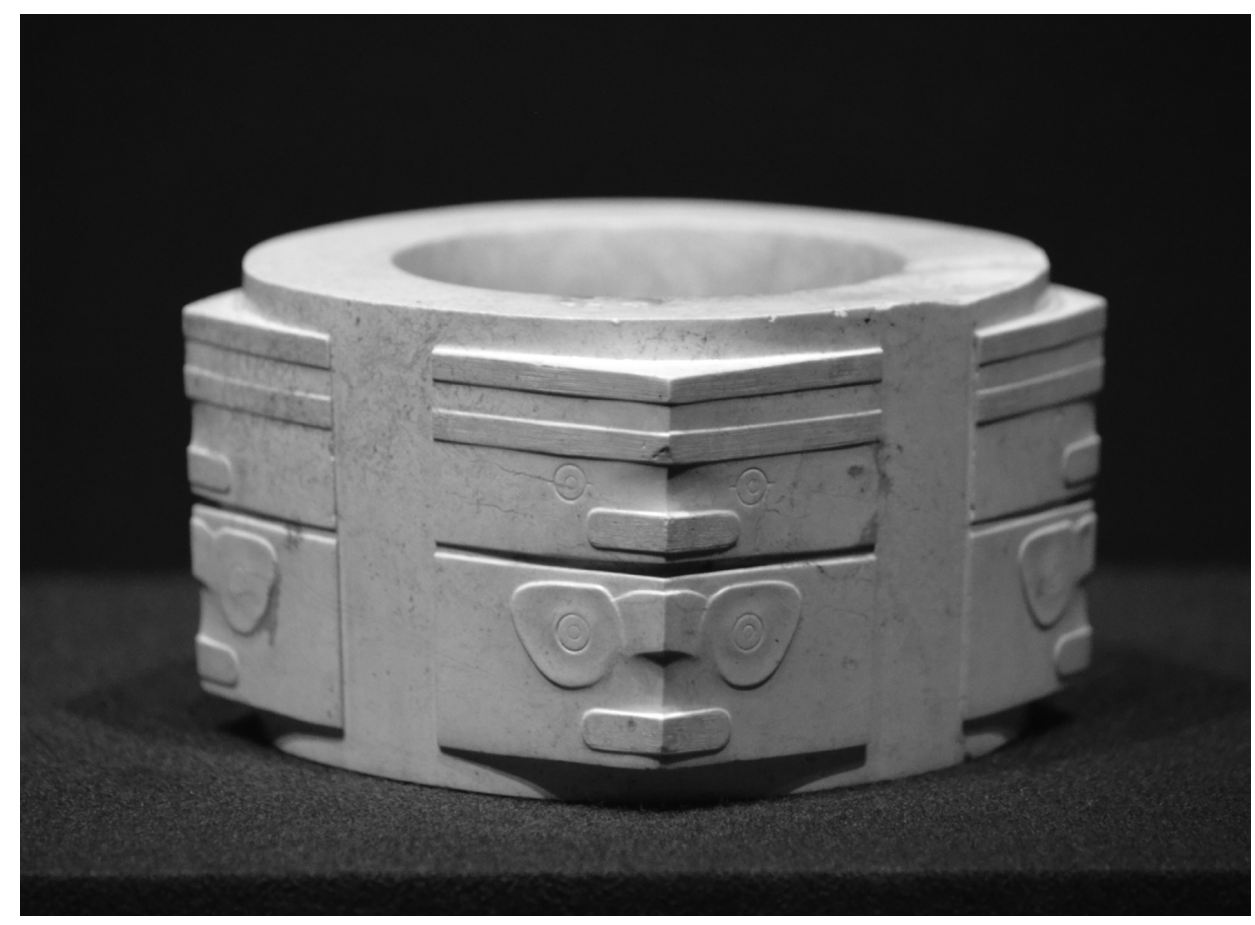

Fig. 6. Ritual object (cong), Liangzhu culture (c. 3200-2000 B.c.), c. 2400. Dimensions: h. 5 cm; diam. $6.6 \mathrm{~cm}$. Excavated at Fuquan Shan, Qingpu County, Shanghai, 1982. Source: Shanghai Museum. (Author's photograph)

authority, other ornamental objects that complemented the sovereign-shamans' attire emerged. These objects made sacred rites even more spectacular. Among these objects are huang pendants composed of various elements in a semicircular form and decorated with the anthropomorphic mask motif.

Ritual weapons and other ornamental jade objects such as scepters (zhang), bead necklaces, and huang became more common in the late Neolithic. They were associated with spiritual and political power in the Liangzhu, Shijiahe (2500-2000 B.C.), and Longshan cultures. Along the banks of the Yellow River, in the present-day provinces of Henan, Shanxi, and Shandong, jade weapons of various types were used in Longshan ritual ceremonies; they included axes (kwei, yue, and $f u$ ) and blades (dao). Such weapons usually display no sign of use, suggesting that they were only used in sacrifices during rituals or merely displayed as symbols of authority (Demattè 2006).

In effect, the Longshan culture constitutes a cultural border between the Neolithic and the Bronze Age. The Bronze Age began approximately 1900 B.C. with the Erlitou culture, located in the same region earlier occupied by the Longshan culture. During the Erlitou culture and throughout the Shang dynasty, jade and bronze ritual weapons followed the shape and design of earlier jade models established by the Liangzhu and Longshan cultures, in the same way that bronze ritual vessels were made in the same shape as Neolithic ceramic vessels.

The Shang dynasty asserted a belief in a celestial hierarchy manifested through natural phenomena. Jade objects took on a vital importance in the context of Shang 


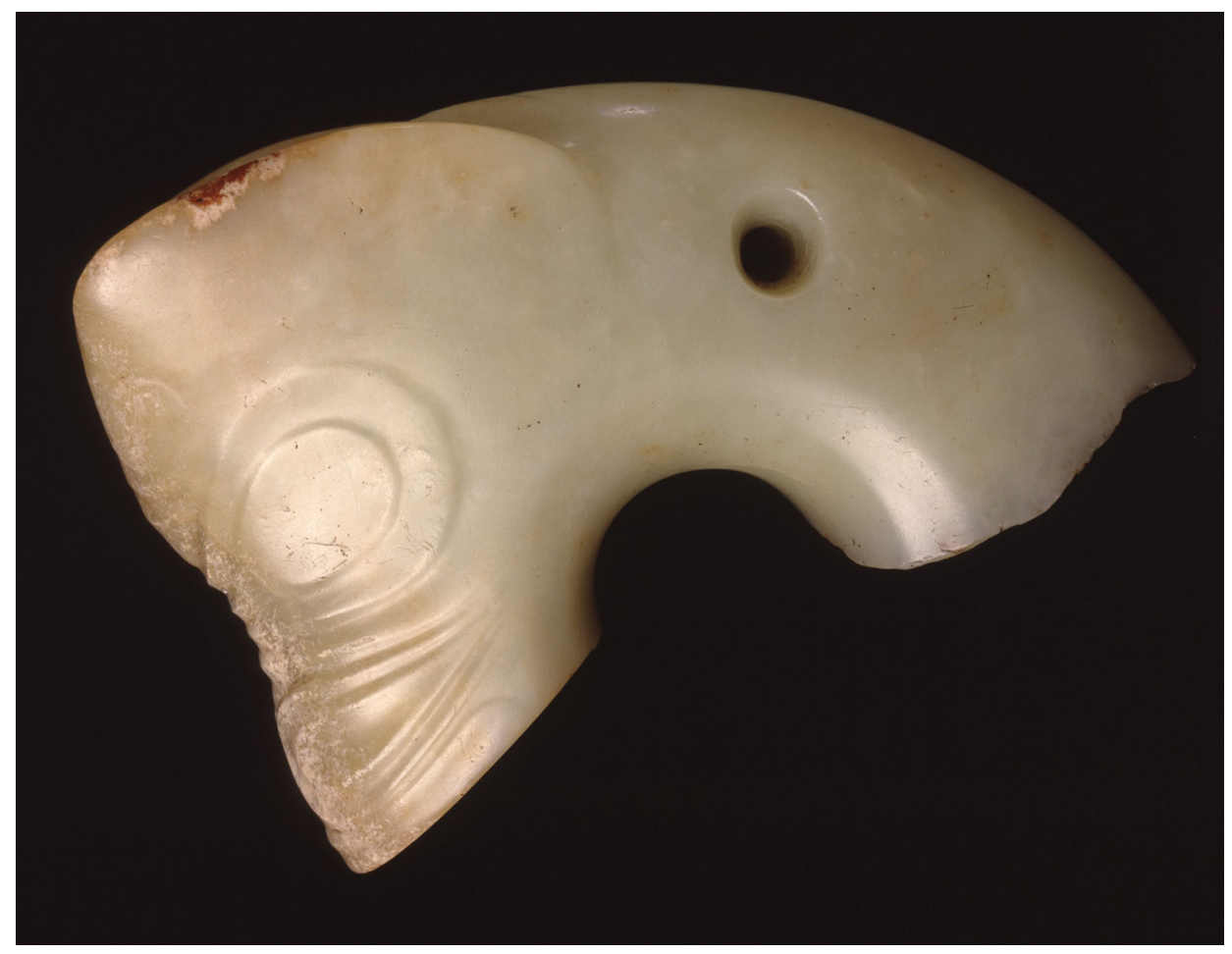

Fig. 7. Jade figure (pig dragon), Hongshan culture, 3500 B.c. Length: $10.4 \mathrm{~cm}$. Source: Museum number 1973,0726.140, British Museum.

rites. One of the few Shang tombs to have been found entirely intact was that of Princess Fu Hao, consort of King Wu Ding (c. 1200 B.C.). This tomb is one of the most important discoveries in Chinese archaeology, not only for the knowledge it has provided on the late phase of the Shang period, but also for the approximately 1500 objects found inside the tomb, of which 468 were made of bronze (weapons, bells, blades, mirrors, and sculptures of tigers), and 75 of jade. Some of these jade objects were from Neolithic cultures, suggesting that the Shang recognized not only their historic value, but above all the spiritual value of their ancestors (Rawson 1992:47$83 ; 2009)$. As far as the iconography and form of these objects are concerned, the only changes that can be perceived are increased artistic sophistication and an updating of earlier forms. These changes resulted from greater mastery of the techniques for working jade, along with new political and cultural environments. Annular-shaped jade objects (including ring-shaped dragons) continued to be highly regarded during the Shang period, although they were usually depicted in two dimensions with the dragons rendered through rigorous, fine incisions on the surface of the jade.

The ritual jades of the Shang dynasty are consistent with the greater ceremonial complexity known from the Neolithic cultures along the banks of the Yangzi River. Weapons and scepters are particularly common, some inscribed with clan insignia. Blades (zhang), presumably used as scepters, along with several types of ge and yue axes have been frequently found in tombs belonging to the Erlitou elite. Later they appear in more peripheral areas of the Sanxingdui culture (c. 1200 в.c.), in the present-day 
province of Sichuan. Besides the absence of evidence that the weapons were ever used, ceremonial and symbolic features of Shang jade and bronze weapons are revealed through their elaborate decorations. Their motifs related to birds, interactions between man and animal, and most commonly the anthropomorphic masks of the taotie 饕䬸 (animal mask), the design of which consists of a frontal or bilaterally symmetrical zoomorphic figure with a pair of bulging eyes (Li 1993) (Fig. 8).

Human figures sculpted in jade date to the Neolithic, specifically from the Hongshan, Shijiahe, and Longshan cultures. It is entirely unknown whether these somewhat realistic figures are personifications of celestial beings, representations of actual individuals with no significant importance, or spiritual leaders who performed rituals. Clay figurines belonging to the Hongshan culture found in Niuheliang appear to be feminine. They have been associated with a temple housing a cult presumably dedicated to a goddess; the head of a woman with inlaid pieces of jade in place of eyes was also found there (Guo 1995).

Jade figurines from the Shijiahe culture are usually represented wearing a headdress and standing in an upright position facing forward, with hands held at the level of their abdomen, suggesting they are making an offering (Fig. 9). Since several miniatures of animals that were traditionally sacrificed during rituals and granted to spirits have been found, it is possible that the human figurines of the Shijiahe culture represent a miniaturized staging of the sacred rituals themselves. Shang dynasty jade statuettes seem to have been modeled upon the Shijiahe figurines: They are represented both frontally and upright with their hands over their abdomen, or on their knees with their hands placed on their legs (Fig. 10). Some figures in these formal positions, dressed in ceremonial attire, were found in Princess Fu Hao's tomb, dated to the late phase of the Shang. These figures probably represented a group of slaves ready to serve offerings to ancestral spirits. Just as vessels and other funerary paraphernalia were made to last forever, symbolic representations of the ritual itself would last for all eternity through the portrayal of personal servants.

\section{FROM SACRED RITUALS TO CEREMONIALS OF POWER}

Since the Shang dynasty, bronze vessels gradually started playing a more important role in the context of sacred rites and thus became increasingly numerous in the furnishing of tombs. These objects were generally placed in groups according to their typology and the specific function for which they were used in the rituals.

Unlike jade objects, whose production occurs throughout the entire history of China, large-scale production of bronze ritual objects and bronze ceremonial tools first emerged around 1900 B.C. and lasted until the end of the Warring States Period in 221 B.C. These chronological boundaries are not precise since bronze tools with a high percentage of copper have also been found in some archaeological sites of the Hongshan, Liangzhu, Yongshao, and Longshan cultures; furthermore, bronze objects continued to be produced during the Qin and the Han dynasties and subsequent periods, although on a significantly smaller scale, as they were steadily replaced by objects made of ceramic, lacquered wood, and other materials.

Bronze objects unearthed in various Bronze Age sites display a significant stylistic evolution. This artistic sophistication reflects a close link between the development of technological skill in casting and molding bronze and the rise of political authority. For example, bronzes dated to the transition period between the Neolithic and 


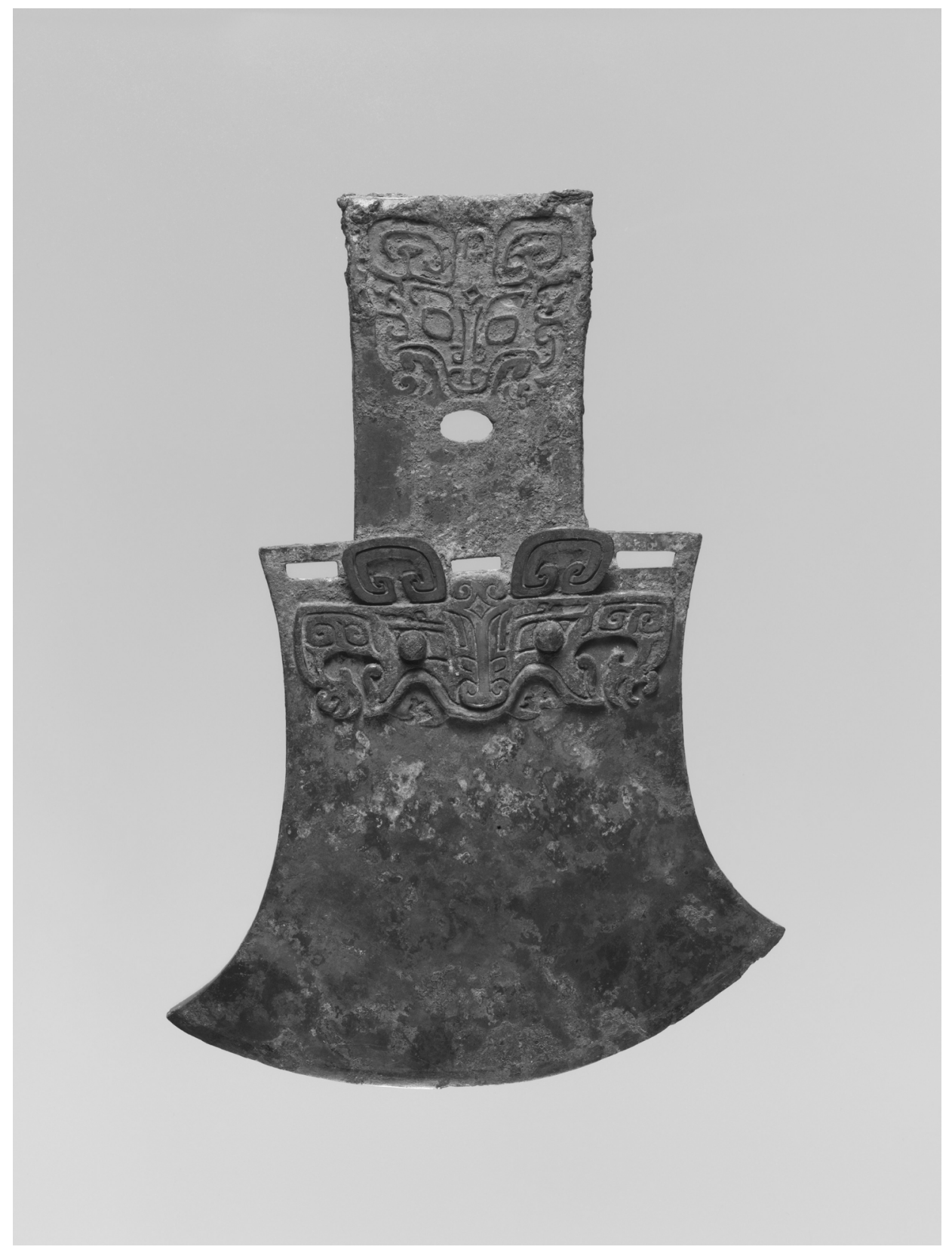

Fig. 8. Bronze ax, Shang dynasty (c. 1600-1046 в.c.), 12th-11th century. Dimensions: h. $24.9 \mathrm{~cm}$; w. 16.2 cm. Source: Accession Number 1985.214.24, Metropolitan Museum of Art, New York, www. metmuseum.org. 


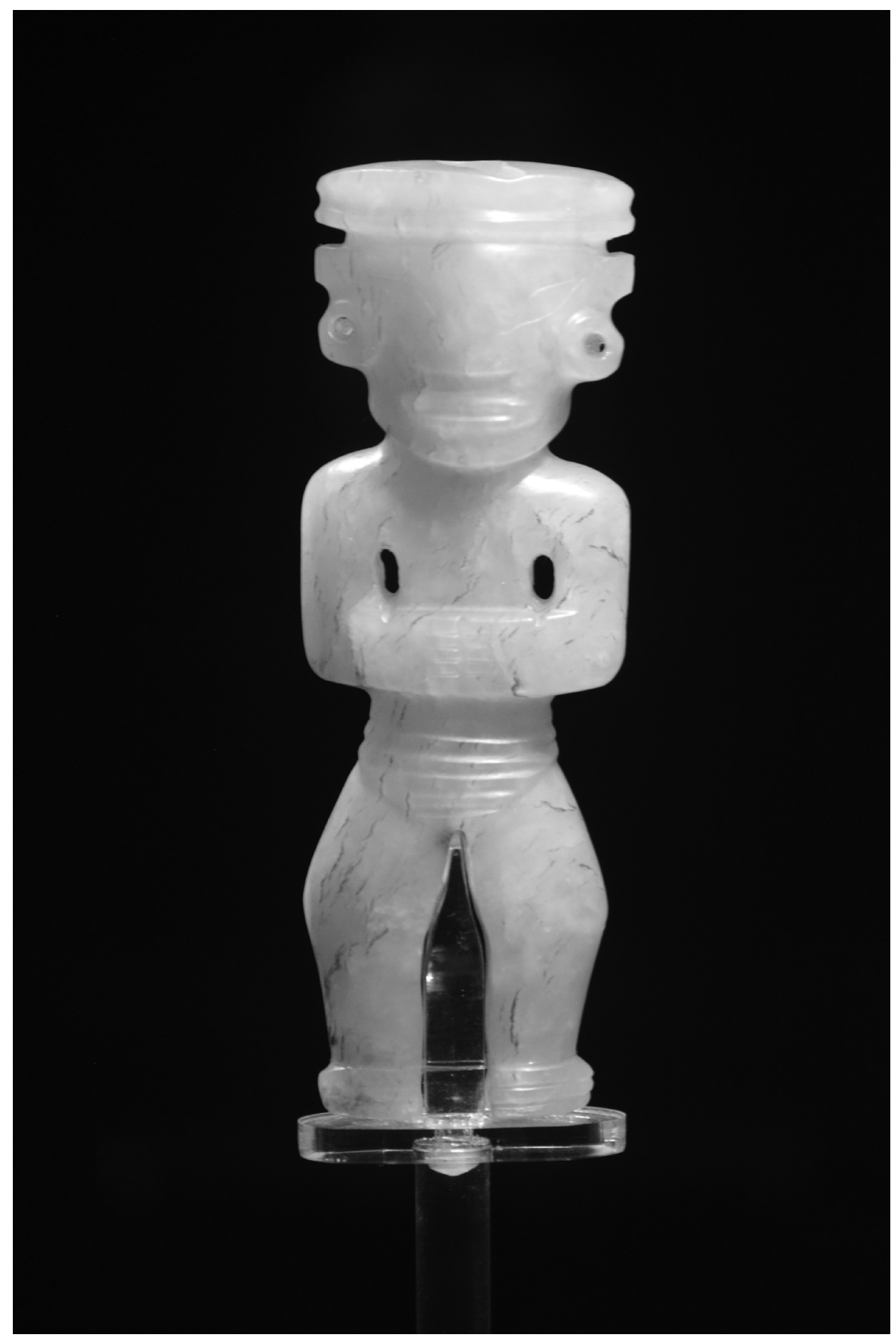

Fig. 9. Human figure, Shijiahe culture (2500-2000 B.c.). Source: Shanghai Museum. (Author's photograph) 


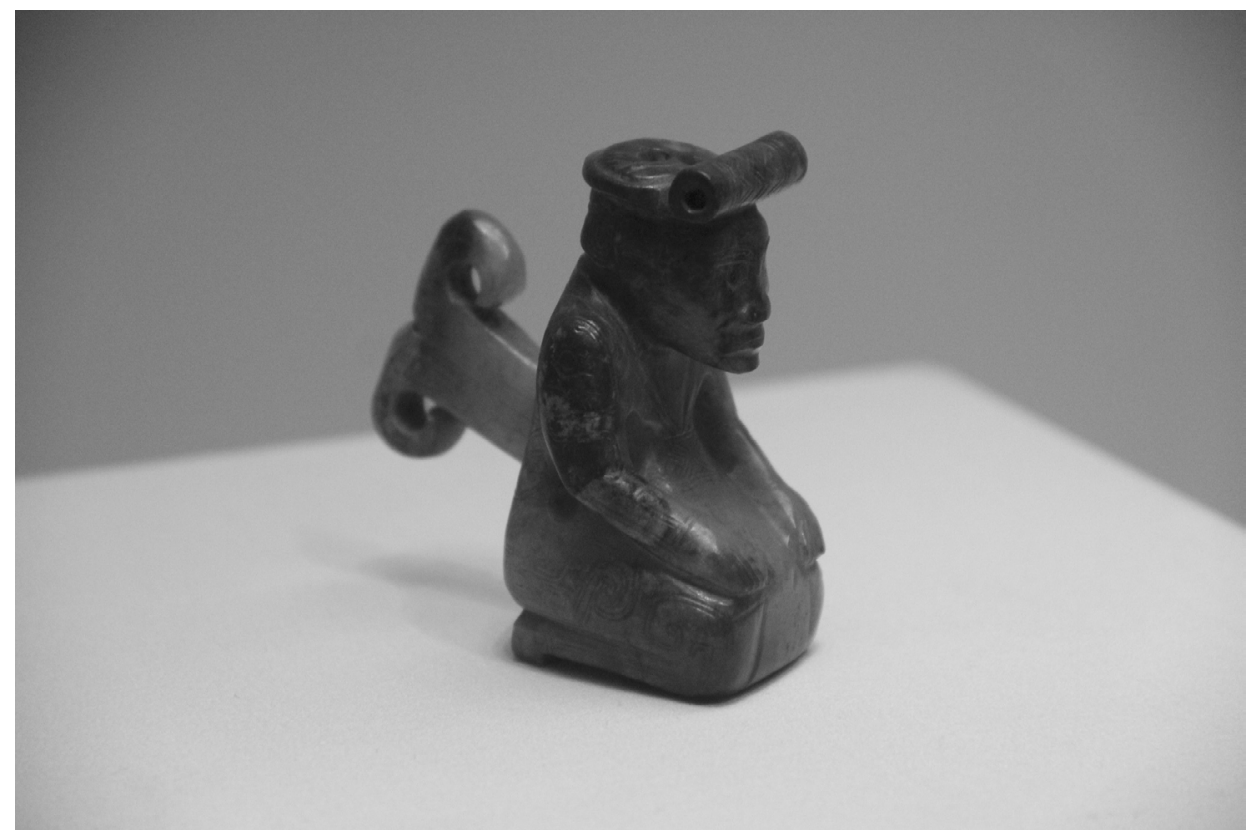

Fig. 10. Human figure, Shang dynasty (c. 1600-1046 B.c.). Source: National Palace Museum, Beijing. (Author's photograph)

Erlitou culture, which Chinese historiography traditionally refers to as the Xia dynasty, commonly appear in a configuration of food vessels (ding) and wine vessels ( $j u e$ and jia) that are either undecorated or have two thin zigzag parallel lines or only a narrow geometric band around the upper part of the body (Bagley 1987, 1990; Chang 1981; Rawson 1992, 2009).

The earliest bronze ritual vessels known today appear to have been forged by hammer, using the same techniques found in Europe during the Bronze Age. The rise of the Shang coincides with the development of new casting techniques, which consisted of molding bronze objects from clay models and molds, by pouring the molten metal into them and filling the space between the two (Bagley 1990; Bavarian and Reiner 2006; Chase 1994). Knowledge of casting and molding techniques was disseminated widely from 1750 в.c. onward; however, fragments of molds that would have been used for the production of bronze objects have been unearthed in some Neolithic archaeological sites, demonstrating that the technique was probably developed during the Neolithic.

Clay models and molds could be used repeatedly, which enabled production of bronze objects on a large scale. Mold sections decorated with several types of iconographic motifs have been found in various archaeological sites of the late phase of the Shang; they were used repeatedly in molding many different types of vessels. The design of ritual vessels changed along with the development of new casting techniques. New shapes with more intricate elements emerged, including joining lids, handles, and other more decorative elements to previously molded vessels. Technical virtuosity gave rise to artistic sophistication and a subsequent decorative stylization of the objects. 


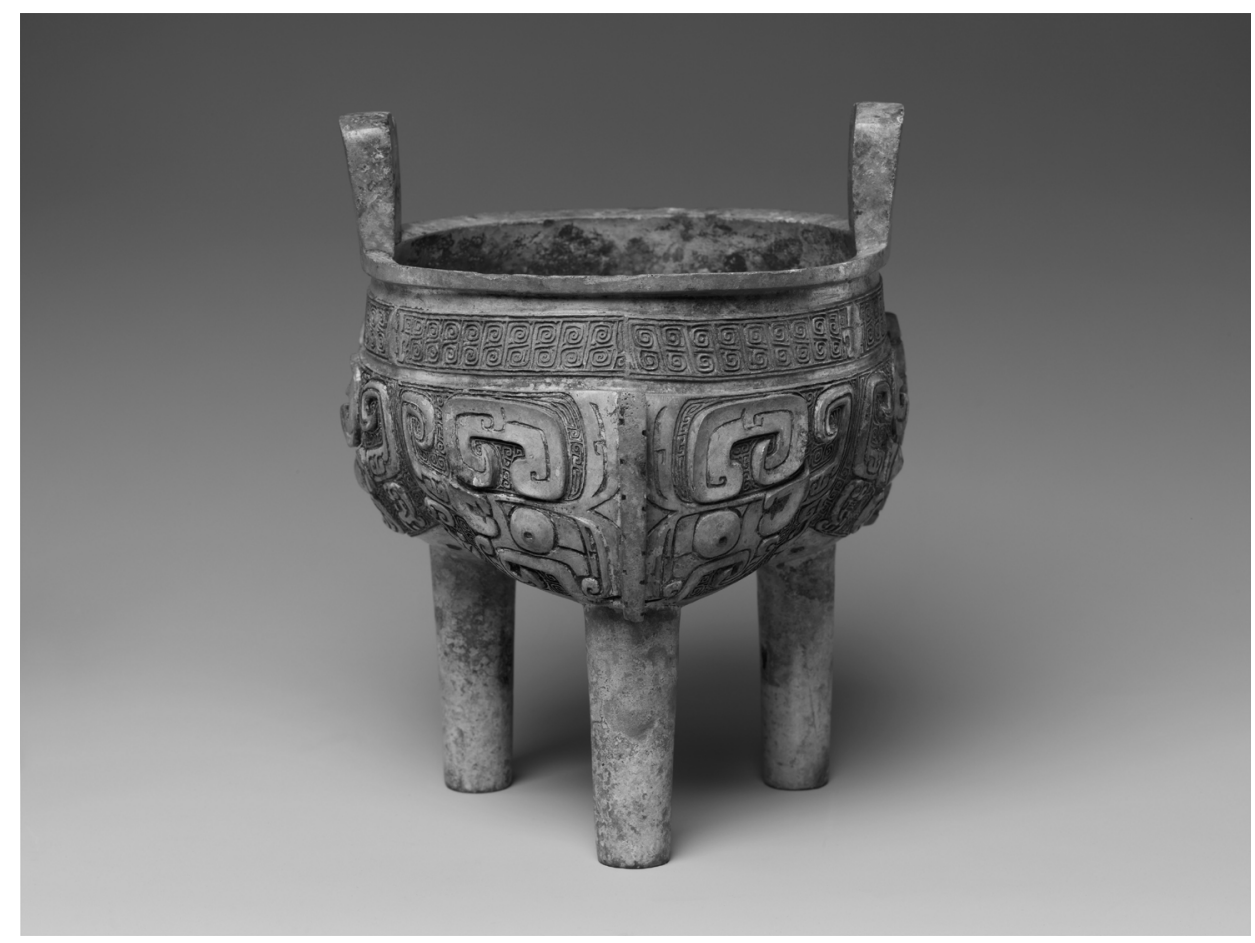

Fig. 11. Ritual lobed tripod cauldron (liding), Shang dynasty (c. 1600-1046 B.c.), 11th century. Dimensions: h. to handles $19.1 \mathrm{~cm}$; h. at $\operatorname{rim} 15.9 \mathrm{~cm}$; w. at handles $5.6 \mathrm{~cm}$. Source: Accession Number 49.136.5, Metropolitan Museum of Art, New York, www.metmuseum.org.

The vast majority of early Shang ritual bronzes are decorated with a characteristic design known as a taotie, which is a stylistic derivation of a mythical animal mask motif found on many ritual jades of the Neolithic (Fig. 11). The taotie presents features of a mythical animal, with bulging eyes in the center, a mouth or lower jaw, heavy eyebrows, ears, and sometimes horns. The taotie normally covers a substantial part of the surface of ritual vessels, revealing an impressive versatility in the ornamentation of the different types of ritual bronze objects.

The stylistic heterogeneity of this motif corresponds to innovations in vessel shapes, as the taotie was adapted to cover different surface spaces on ritual bronzes. Some scholars therefore suggest that the taotie was merely a decorative element designed to make the most use of available space, rather than an iconographic representation of some part of the spiritual imaginary of the Shang (Bagley 1993; Loehr 1953). However, besides probably having been derived from the animal mask motif found on many Neolithic ritual jades, it is important to add that the taotie is an imagined being, one of many other animals, both real and mythical, depicted on the surfaces of ritual bronzes. Zhou- and Han-period texts such as the Spring and Autumn Annals (Lushi Chunqiu 氏春秋), the Classic of Mountains and Seas (Shan Hai Jing [海), and the Han dynasty dictionary Explaining and Analysing the Characters (Shuowen Jiez $i$ 解字) identify some of the imaginary animals depicted on ritual bronzes, including the taotie (an animal without a body), the feiyi (a serpent with one head and two bodies), the kui (a black animal similar to an ox, but without horns and only one leg), and the long 
(the most common type of dragon). Although these texts date from later periods, they assert that these animals represented important aspects of primordial Chinese myths concerning the connection between Heaven, Earth, and Water (symbolized by the dragon); the devastating consequences of drought (brought by the feizi if anyone catches sight of it); and of the destructiveness of some spirits (such as the specter of the one-legged kui).

These mythical animals stand for the devastating forces of the cosmos, which are manifested through the elements of nature (drought, floods, fire, epidemics), and that determine human welfare. In the imaginary of earlier pre-state societies, mandevouring beasts were common. They symbolized the personification of the devastating action of nature and the vulnerability of humankind. Hybrid mythological animals, commonly combining the serpent with winged animals, connected Heaven and the aquatic world. ${ }^{4}$ Such mythological animals represented the wrathful judgment of a supreme being that sustains the universe and controls the welfare of humankind. This is an archetypical representation of a (heavenly) father devouring his sons (humans). Representing the wrath of a god against humans is a reminder to follow the god's commandments through obedience and a righteous way of life. Humans were expected to perform rites and sacrifices, make food and wine offerings in order to gain divine favor, and thus turn the god's devastating forces away from humankind. Regardless of the specific meaning they held during the Shang dynasty, the mythological animals depicted on bronze objects associated with sacred rituals corresponded to an imaginary that is shared with other cultural traditions, both coexistent and subsequent, also including sacrificing animals and making offerings of food and wine or other inebriant drinks.

Real animals are frequently represented on the ritual bronzes of the Anyang period. Owls and other birds, cicadas, silkworms, turtles, hares, elephants, rhinoceros, deer, oxen, horses, water buffalo, tigers, and wild boar were some of the most common. As already mentioned, the representation of birds, turtles, cicadas, and silkworms derives from the Neolithic imaginary and held specific significance in the context of sacred rituals. Just like in Neolithic jades, in bronze ritual objects these animals establish a connection between Heaven and Earth by virtue of their natural characteristics. They were increasingly displayed in more stylized forms, as they were adapted to the available space and form of ritual vessels.

A wider range of animals was used in divinatory rituals as well. Apart from the fact that oracle bones, used to literally communicate with ancestral spirits, were predominantly turtle shells and ox scapulae, it is not uncommon to find oracle inscriptions on bones from other animals such as sheep, wild boar, horses, deer, and water buffalo. Referring to several passages from Zhou texts, Kwang-chih Chang argues that animal sacrifices were part of the paraphernalia that was essential to the performance of rituals aimed at establishing a connection between Heaven and Earth (1981). The relation between oracle bones and animal sacrifice, offered to the ancestral spirits and served in the ritual vessels, is reflected in the representation of such animals on the ritual vessels, according to Zuo Zhuan's Spring and Autumn Annals (Chunqiu Zuo Zhuan 春秋左专):

The tripods [ding] do not matter; virtue does. In the past when the Xia dynasty was distinguished for its virtue, the distant regions put their $w u$ (物) $)^{5}$ into pictures and the nine provinces sent in copper as tribute. The tripods were cast to present those $w u$ (物). One hundred different $w u$ (物) were presented, so that people could distinguish divine 
from evil. Thus the people when they went among the rivers, marshes, hills, and forests did not meet with the injurious things, and the hill-spirits, monstrous things, and waterspirits did not meet with them. Hereby a harmony was secured between the high and the low, and all enjoyed the blessing of Heaven. When the virtue of Jie [last king of the $\mathrm{Xia}$ ] was all-obscured, the tripods were transferred to the Shang dynasty, and for six hundred years the Shang enjoyed its ruling status. Finally, King Zhou of the Shang proved cruel and oppressive, and the tripods were transferred to the Zhou dynasty. (Legge 1872:293)

The relevance of this excerpt lies in its clear reference to the function of the ritual vessels (and the iconographic elements represented on them) in securing harmony between Heaven and Earth by means of communicating with ancestral spirits. It also demonstrates the knowledge that existed, particularly during the Shang and the Zhou dynasties, concerning the circulation of bronze ritual objects from the areas of central power with the peripheries, namely with peoples west and south of China. In conclusion, there seems to exist a correlation between the sacrificing of certain types of animals, the use of their bones to communicate with ancestral spirits, and the representation of these animals on the surface of bronze ritual vessels, which were used to serve ceremonial banquets that appeased the voracious forces of nature and spirits that threatened human welfare.

Although the decoration of ritual bronzes may bear an iconographic significance that mirrors and mediates the relationship between humans and the sacred, including life after death, it is also true that the richness of the decorations corresponds to a set of aesthetic principles that are demonstrated in the high variety of styles and forms arising from artistic creativity. Artistic sophistication and an increasing mastery of casting and molding techniques provided a wide array of decorative possibilities, which led to combining different iconographic elements according to the physical characteristics of the objects. In many cases, certain types of elements were introduced and the usual forms were redesigned so as to fill the space available. In so doing, they lost any meaning they might earlier have held. After a period strongly influenced by the realistic representation of animals, which was characteristic of the regions of southern China, the late phase of the Shang saw a reinvention of classic styles of taotie motifs and the inclusion of other imaginary beings and abstract designs, indicating a more aesthetic and fashionable perspective toward the visual appearance of the object as a whole.

Two characteristics of ritual bronze decoration are balance and symmetry. Bronzes were often made using illusion-creating techniques that suggest an unconscious grouping of different elements. Symmetrical pairs of animals and other decorative elements commonly appear on the upper bands of the body of a vessel or on its frontal area, on either side, or on each of the vessel's legs (Fig. 12). Such paired elements were usually separated by vertical protrusions designed to maintain their symmetry with each other and consonance with other decorative elements. Regardless of the symbolic charge attributed to symmetry, the visual effect of symmetry inherently stimulates the primary senses of human consciousness. That is to say, the visual cortex reacts emotionally to visual stimuli that suggest balance, proportion, and harmony. ${ }^{6}$

In addition to symmetry, the decorations on many ritual vessels display an interesting feature that occurs in many other ancient cultures around the world. This feature was termed "split representation" by Claude Lévi-Strauss (1963). This is characterized by a symmetrical, frontal representation of an animal head that simultaneously depicts 


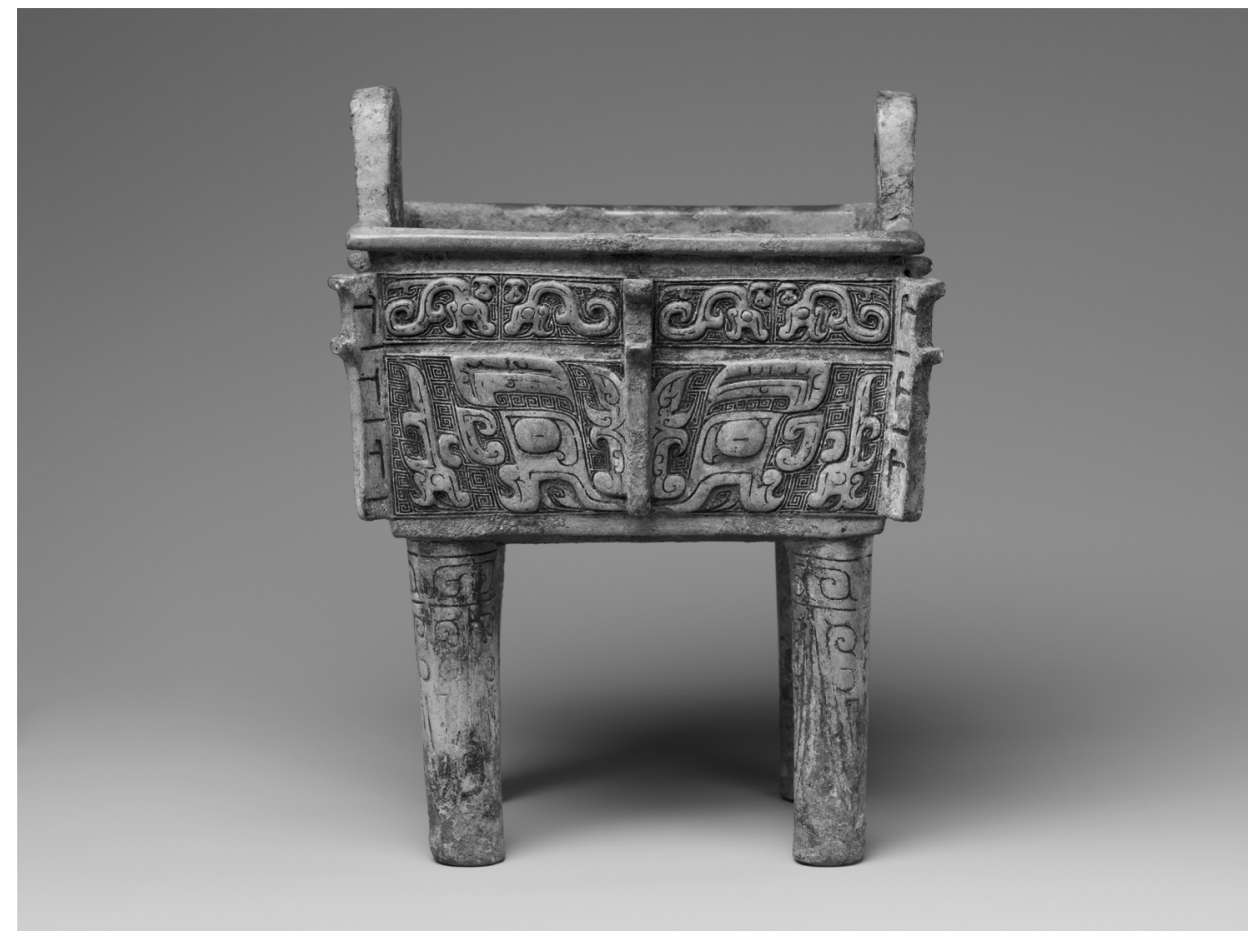

Fig. 12. Ritual tetrapod cauldron (fangding), Shang dynasty (c. 1600-1046 B.c.), 12th-11th century. Dimensions: h. 22.9 cm; w. 15.2 cm; diam. 17.8 cm. Source: Accession Number 49.135.2, Metropolitan Museum of Art, New York, www.metmuseum.org.

the head of two animals in profile, one to the left and the other to the right. The left half of the animal's face corresponds to the head of the animal on the left seen in profile, while the right half of the animal's face corresponds to the head of the animal on the right, also seen in profile. It is common to find this effect in right-angled vessels. Viewed at an angle, the animal representation will be seen face-on, but when the vessel is viewed from the front there will be an animal in profile represented on either side. Although Claude Lévi-Strauss interpreted this characteristic as a technical need for the representation of a three-dimensional element on a two-dimensional surface, and Kwang-chih Chang (1981) perceived it as being a reflection of the dualism present in Shang thought and institutions, it seems to be a merely creative but powerful way of decorating the ritual vessels. This illusionary feature is capable of triggering an emotional response that highlights the uniqueness of the bronze object and demonstrates the social status of the owner. ${ }^{7}$

As we see in the next section, as political authority and prosperity under a king's rule overlapped or replaced the importance of sacred rites, the symbolic language and the significance of certain elements represented in ceremonial objects gave way to a predominantly ornamental artistic sophistication. Precious objects such as jade implements and bronze vessels ceased to be uniquely related to communication with the ancestral spirits. Instead, as they were more oriented to strengthen political power and the attainment of honors, they were increasingly used to celebrate important events and record the actions of elite individuals. 


\section{JADE AND BRONZE AS SYMBOLS OF POLITICAL AUTHORITY}

According to written sources such as the Book of Documents, also known as the Book of History (Shujing 书经), when the Zhou defeated the Shang around 1045 B.C., they evoked the principle of the Mandate of Heaven and claimed to have emerged as victors only because the ancestral spirits so intended, since the behavior of the Shang was morally unacceptable. As the Zhou hegemony was established, ritual proceedings were restructured. This exerted a significant influence on the artistic creativity and technical knowledge involved in the production of jade and bronze objects. Meaningful changes concerning the organization of the state and ritual proceedings generated a rupture with some traditions of the Shang. These changes were reflected in the production of ritual objects, both in terms of shape and decoration. For example, the number of wine vessels found in burials significantly decreased in favor of a greater preponderance of food vessels of the $x u$, gou, and gui types.

Bronze ritual vessels increasingly became a reflection of political power and an instrument for conveying social hierarchies and political and military achievements. Thus, while Shang ritual bronzes usually included a single or small number of characters identifying their owner, Zhou ritual bronzes displayed long inscriptions referring to political matters, land transfers, military victories, and the attainment of honors or social status. While the stylistic richness of the decorations and the formal variety of Shang ritual bronzes only enable us to deduce their owner's importance and status, the long inscriptions on the Zhou ritual bronzes record concrete facts related to the activities of specific individuals or historical events. Inscriptions recording facts about the life of one or more individuals served not only to impart their achievements or the virtues of their actions to people in their own time, but also to influence future generations, so they could be proud of their ancestors and follow their virtuous examples. Many of such ritual vessels dated from the Western Zhou dynasty contained long inscriptions and were deposited in hoards alongside bronze ritual vessels of other periods. This fact suggests they might have been kept in the family for several generations, only to be buried in a crisis or in haste so that their owners could escape attackers unhindered or to prevent the objects from being plundered (Feng 2006; Fong 1980; Rawson 1999).

Substantial changes in the decoration of ritual vessels were not introduced in the early Western Zhou, but it is common to come across stylistic reformulations of the representation of the real and mythological animals normally found on Shang-period vessels. The Western Zhou placed a special emphasis on goats and water buffalo, although taotie and long dragons were also common.

The social and political contexts of the Zhou favored narrative descriptions (through inscriptions) over Shang-style ornamentation. Thus, many of the shamanistic elements inherited from the Shang were replaced by a merely ornamental repertoire around 950 в.C. that was marked by the strong presence of bird designs instead of the traditional taotie and other zoomorphic representations of the Shang and early Western Zhou. Influenced by cultures in south and southeastern China, stylized representations of birds with prominent beaks, curled feathers on their heads, and long tails became common on both bronze and jade objects (Rawson 1999). Techniques for casting and joining precast components were developed throughout the middle phase of the Western Zhou. For example, handles shaped like animals or ropes, lids, and other decorative elements cast beforehand were joined to the vessels (Fig. 13). 


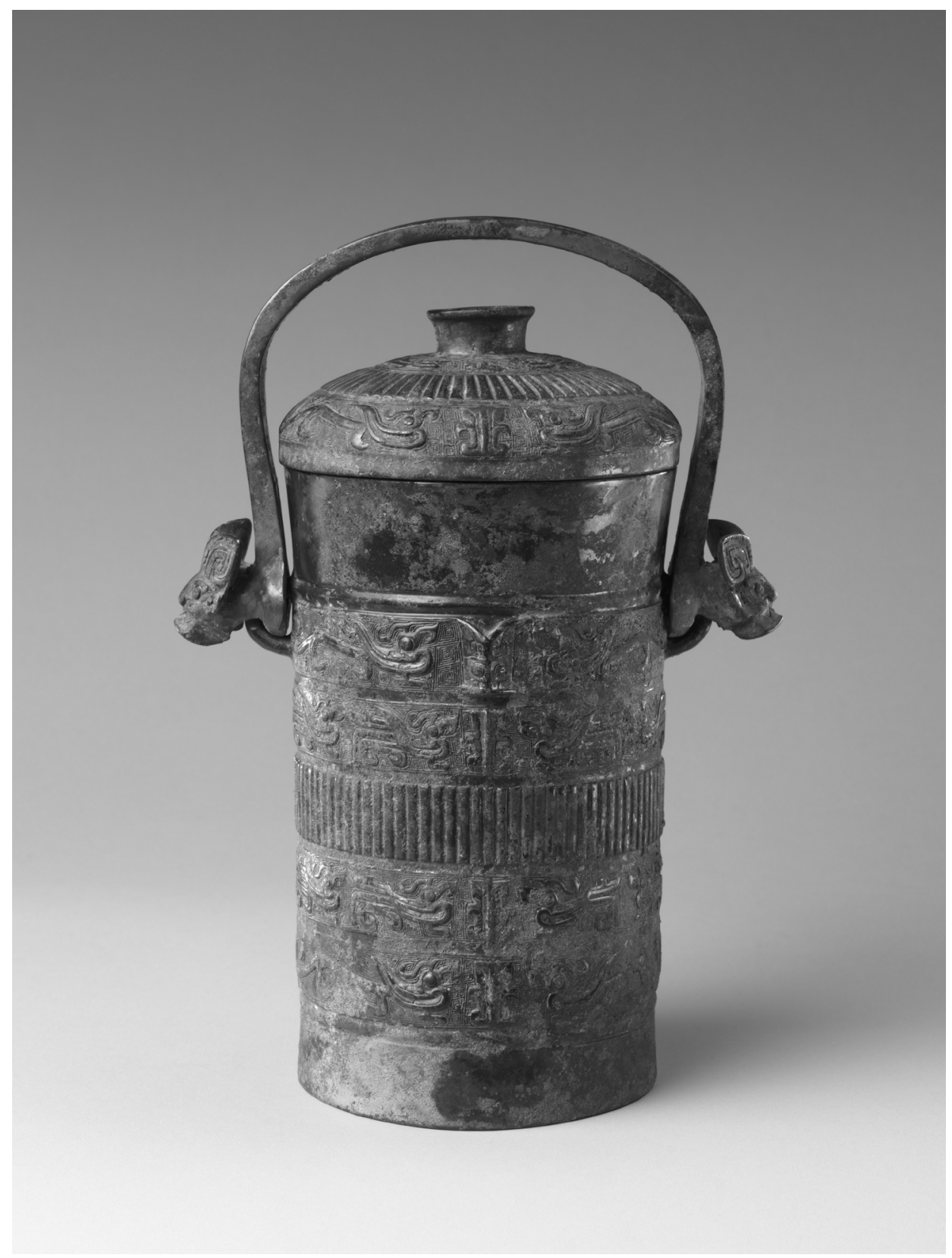

Fig. 13. Ritual wine container (you), Western Zhou dynasty (1046-771 B.c.), 11th-10th century. Height: $27.6 \mathrm{~cm}$. Source: Accession Number 49.135.5a, b, Metropolitan Museum of Art, New York, www.metmuseum.org. 
During the late phase of the Western Zhou (c. 771 в.C.), zoomorphic representations started disappearing and giving way to narrow wavy bands, vertical grooves, and other geometric elements, relegating the representation of animals to the handles, legs, and other accessorial precasted elements. As a result of this sudden reconfiguration of the sacred rites, along with the importance the Zhou attributed to food during the rituals, food vessels of the ding and gui types became extremely common. This may be due to the large surface area of the interior of such vessels, where inscriptions were usually placed. However, wine vessels especially of the you and zun types also became more common. They were often cast in animal shapes. The zun vessels are the primitive form of the small bronze sculptures in the shape of animals that became popular during the Warring States Period, often decorated with gold, silver, or copper and inlaid with turquoise, jade, or other kinds of stone.

During the early phase of the Western Zhou, ritual jades retained the same design as those from the Shang period, although production decreased relatively. The great majority of jade objects were carved in the shapes of animals. One common motif blended a man with a bird. The representation of fish was also very common; these were often used as pendants. Other types of jade objects, such as ge weapons, $b i$ discs, and cong tubes, became increasingly rare. On the other hand, new types of ritual jade objects emerged during the middle phase of the Zhou. For example, discovered fragments of assorted sizes form masks, suggesting that those fragments were placed over the face of the dead. The bird motif with prominent beak, curled feathers, and long tail became predominant in the decoration of jade surfaces, as advanced incision and carving techniques became a feature of the technical and artistic craftsmanship of the late period of the Western Zhou.

Around 475 B.C., during the Warring States Period, Chinese artists started molding bronze on a large scale using the lost wax technique, especially in producing small objects and ritual vessels that furnished the tombs of the most prominent royal and aristocratic figures. Such technological developments and artistic creativity were fostered by the need for ostentatious displays of political and military power that reflected the authority, status, and prosperity of their owners. Also during the Warring States Period, techniques for using gold, silver, and copper inlays, and sometimes combinations of these precious metals, were developed. These objects were cast with recesses open on the surface to hold the intended decoration. When these recesses were subsequently filled with gold, silver, or copper, it created an impression of chromatic contrast and natural embellishment and enrichment. Decorations on this type of vessel often depicted ritual activities, such as war and hunting scenes and groups of people dancing.

I assume that these techniques and artistic innovations regarding the shape of some of the objects derived from contact with coexistent peoples of the Near and Middle East, since inlays in gold, silver, and copper were a common practice in Egypt and Persia and already had a long tradition in Persian art. New shapes that emerged in China, such as the $h u$ wine vessels, closely emulate pear-shaped vessels with high, cylindrical necks that were very common in Achaemenid Persia and in some areas of the Eastern Mediterranean (Fig. 14). ${ }^{8}$

Bronze objects from each period show a clear affinity with the political and military situation that China was going through at each time. During the Shang and the early Zhou periods, sacred rites constituted an important part in state affairs. Consequently the majority of bronze objects were designed to function specifically in the 


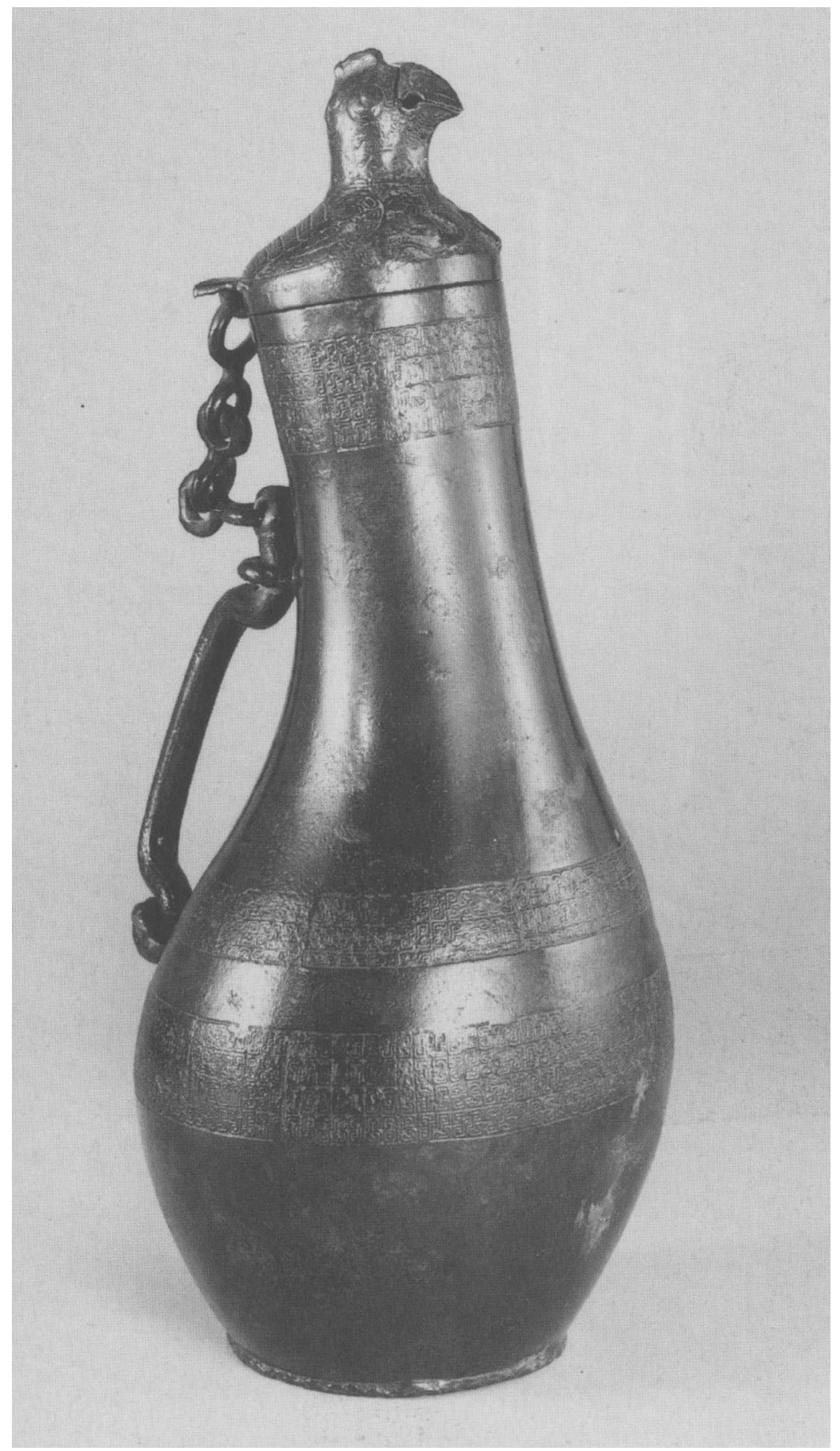

Fig. 14. Bronze flask (hu), Eastern Zhou dynasty (770-221 в.c.). Dimensions: h. $32 \mathrm{~cm}$; diam. $6 \mathrm{~cm}$. Source: Museum Number 1973,0726.26, British Museum. 
context of funerary and shamanic practices. When political instability spread across China as great states arose and fought for political and military hegemony, objects were increasingly intended to reflect the health and prosperity of warlords and political sovereigns. For example, the tiger-shaped tally, traditionally called a hufu, was a two-piece object that stood for political authority and the ability of a general to command troops on behalf of the ruler. Some of the most exuberant bronze objects exemplifying the climate of military instability during the Warring States Period were adornments on military attire: namely belt buckles with gold, silver, or copper and often turquoise inlays. Scabbards in bronze and jade were also common.

After the unification of China, under the sovereignty of the first emperor, Qin Shi Huang Di, a political shift occurred that contributed to a short-lived decline in the importance of bronze in ritual practices. After the fall of the Qin dynasty, however, the Han re-invigorated the production of bronze objects and made considerable innovations, including in their function in the funerary context as well as their artistic significance. Han bronzes included animal-shaped censers and lanterns that reflected new views on immortality and life after death manifested by the influx of Buddhist beliefs.

In the transition between the Warring States Period and the Han dynasty, artisans experimented with techniques for combining jade and bronze, probably based on inlay techniques using copper, gold, and silver. Jade-bronze combinations are still very rare, however. In the collections of the Hunan Provincial Museum, there is a cup in golden bronze and jade inlays that comes from Tomb 2, belonging to the family of Li Cang, Marquis of Dai and Chancellor of the Prince of the State of Changsha. According to the registry inscription that lists information about the objects included in the funerary chambers, the Li Cang family tomb was sealed in 168 B.C. (Xiong and You 2006).

During the Warring States Period, the political division between the great states gave rise to a moral crisis and to a period of great instability, propitious for the dissemination of Taoism and Confucianism throughout the fifth century B.C. The Classics, such as the Book of Rites (Li Ji 礼记), demonstrate the importance of jade as a symbol of the knowledge and morality of the virtuous man. When Zi Gong, one of Confucius' disciples, questioned his mentor on the importance of jade for the noble man, Confucius replied:

It is not because the soapstone is plentiful that he thinks but little of it, and because jade is rare that he sets a high value on it. Anciently superior men found the likeness of all excellent qualities in jade. Soft, smooth, and glossy, it appeared to them like benevolence; fine, compact, and strong,--like intelligence; angular, but not sharp and cutting,- - like righteousness; hanging down (in beads) as if it would fall to the ground, like (the humility of) propriety; when struck, yielding a note, clear and prolonged, yet terminating abruptly,- - like music; its flaws not concealing its beauty, nor its beauty concealing its flaws,- -like loyalty; with an internal radiance issuing from it on every side,- - like good faith; bright as a brilliant rainbow, - like heaven; exquisite and mysterious, appearing in the hills and streams, - like the earth; standing out conspicuous in the symbols of rank, - like virtue; esteemed by all under the sky, - like the path of truth and duty. As is said in the ode: Such my lord's car. He rises in my mind, lovely and bland, like jade of richest kind. (Legge 1885:464)

In the time of Confucius it was common for all noble and exemplary men to wear jade objects as symbols of their social status and the moral virtues that characterized 
them. This gave rise to a range of new meanings associated with jade, completely distinct from those jade had held throughout the previous periods, even if objects still retained common iconographic elements or were a recast of old types. Bi discs significantly decreased in size and evolved in the direction of a remarkable diversification, so as to be used as clothing accessories, usually hung from the waist or adapted to long chest pendants.

For Taoists on the other hand, jade was viewed as an immortal substance, a spiritual source of purity and truth, and an object with alchemic properties that favored longevity, becoming particularly popular during the Warring States Period and the Han dynasty. The funerary rites of members of the aristocracy during the Warring States Period and the Han dynasty reveal jade objects being placed in strategic parts of the body, namely the mouth and the eyes, with the view of preventing natural decomposition. In some cases, jade masks and suits have been unearthed, similar to those found in the tombs of Liu Sheng and Dou Wan in Hebei Province, and of Zhao Mo, known as King Nanyue, in Guangzhou. According to the Book of the Later Han or History of the Eastern Han (Hou Hanshu 后汉书), compiled by Fan Ye in the fifth century, the hundreds of jade plaques that made up the suit were joined by means of wire, which could be made of gold, silver, or silk, corresponding to the person's status or position in Chinese aristocracy. However, the archaeological evidence indicates that these practices were not always duly employed.

Despite not being as numerous as during the Warring States Period, the sets of jade objects found in tombs of the Han dynasty are often symbolical representations of imperial authority, where the dragon is the most prominent iconographic element as a symbol of imperial power. The dragon is often depicted juxtaposed in harmony with the tiger, symbol of military power. During the Han, a new attitude toward the historical events of the first sovereigns emerged, and the practice of collecting objects from those periods became common. Consequently, some of the more usual shapes, like discs, were stylistically redesigned to suit contemporary trends in ornamentation. Meanwhile, interest grew in collecting exotic objects that were entering China through the Silk Road trade, especially unique objects brought from the Persian world. These exotic objects inspired new artistic forms in China. Libation cups, commonly known as rhytons (called takuk in Persia) were some of the rarest objects, but they spread throughout Asia Minor and influenced China. In the tomb of King Nanyue of the Han dynasty, along with silver boxes imported from Persia was a jade libation cup in the shape of a rhinoceros horn; the shape of the cup was probably based on Persian models (Wu et al. 2007).

The tombs of important aristocratic figures were furnished with countless objects made of different materials. Musical instruments, lacquered wooden statues, silk, furniture, and exotic boxes have been found in conjunction with jades and collections of different types of bronze vessels. During the Warring States Period, the presence of large numbers of bells and other musical instruments suggests that funerary rites were followed by an elaborate ceremony attended by a large audience of guests, reflecting the greatness of the deceased and the desire to prolong life after death.

During the Han dynasty bronze became less important in sacred rites and funerary practices. Eventually, Buddhist iconography influenced the Han imperial court and gave rise to a substantial sociological transformation, not only regarding thought, religion, and politics, but also in regard to art, through the introduction of new 
representational codes, new materials and techniques, and the role that Chinese painting had after the fall of the Han dynasty. Nevertheless, from the Han dynasty to the present, jades and bronzes of ancient China have been preserved and regarded as the most important cultural relics of China.

\section{ACKNOWLEDGMENTS}

This work was supported by Fundação para a Ciência e Tecnologia [FCT/SFRH/ $\mathrm{BPD} / 79355 / 2011]$.

\section{NOTES}

1. Shamans used the bones and shells of various animals, especially turtle plastrons and ox scapulae, for divination. They inscribed them with questions directed toward ancestral spirits. The oracle bones were subsequently heated in a fire and the stress cracks that appeared were then interpreted. These readings were then carved on the opposite side, close to the edge (Keightley 1978, 1989).

2. On Erlitou culture during the transition between the Neolithic and the Bronze Age, see Allan 2007.

3. On the sacred dimension of Heaven and the Mountain, see Eliade 1949 and Durand 1992.

4. On myths related to the dragon or serpent in the mythological traditions of Indo-European cultures, see Dumézil 1968-1971 and Watkins 1995. In the mythology of Mesoamerican cultures, Kukulkan and Quetzalcoatl were represented as a man-devouring feathered serpent in Yaxchilan and Chichen Itza, and were probably inspired by the same motif rendered at the Juxtlahuaca Cave, of the Olmec culture (Joralemon 1996).

5. Although some authors translate the character $w u$ (物) as object or thing, it can also be translated as creature, which in this context seems more correct.

6. These approaches have been developed by neuroscientists in their effort to establish a relationship between artistic creativity and the functioning of the visual cortex (Ramachandran 2005; Zeki 1999).

7. On the resolution of problems of visual perception and the emotional responses of the limbic system, see the concept of "grouping" in Ramachandran 2005.

8. Despite it being assumed that the Silk Road was established following the missions of exploration to the west led by Zhang Qian, around 140-134 B.C., it is probable that caravan routes that enabled the transport of goods in the steppes of Central Asia already existed (Liu 2010).

\section{REFERENCES CITED}

Allan, Sarah

1991 The Shape of the Turtle: Myth, Art, and Cosmos in Early China. Albany: State University of New York Press.

1993 Art and meaning, in The Problem of Meaning in Early Chinese Ritual Bronzes: 9-33, ed. Whitfield Roderick. London: SOAS. Colloquies on Art \& Archeology in Asia No. 15.

2007 Erlitou and the formation of Chinese civilization: Toward a new paradigm. The Journal of Asian Studies 66 (2) : 461-496.

BACHELARD, GASTON

1943 L'air et les songes. Essai sur l'imagination du mouvement. Paris: Librairie José Corti.

BAgLEY, ROBERT

1987 Shang Ritual Bronzes in the Arthur M. Sackler Collections. Washington, D.C.: Arthur M. Sackler Foundation.

1990 Shang ritual bronzes: Casting technique and vessel design. Archives of Asian Art 43:6-20.

1993 Meaning and explanation, in The Problem of Meaning in Early Chinese Ritual Bronzes: 34-55, ed. Whitfield Roderick. London: SOAS. Colloquies on Art \& Archeology in Asia No. 15.

Bavarian, Behzad, and Lisa Reiner

2006 Piece Mold, Lost Wax and Composite Casting Techniques of the Chinese Bronze Age. Northridge: California State University Press.

Chang, KWANG-CHIH

1981 The animal in Shang and Chou bronze art. Harvard Journal of Asiatic Studies 41 (2):527-554. 
1999 China on the eve of the historical period, in The Cambridge History of Ancient China: From the Origins of Civilization to 221 B.C.: 37-73, ed. M. Loewe and E. L. Shaughnessy. Cambridge: Cambridge University Press.

Chase, W. Thomas

1994 Chinese bronzes: Casting, finishing, patination and corrosion, in Ancient and Historic Metals: Conservation and Scientific Research: 85-117, ed. David A. Scott, Jerry Podany, and Brian B. Considine. Los Angeles: The Getty Conservation Institute.

Childs-Johnson, Elisabeth

1988 Dragons, masks, axes and blades from four newly documented jade-working cultures of Ancient China. Orientations 19 (4):30-41.

Demattè, Paola

2006 The Chinese Jade Age: Between antiquarianism and archaeology. Journal of Social Archaeology $6: 202-226$

DumÉZIL, GEORGE

1968- Mythe et épopée. Paris: Gallimard.

1971

Durand, GiLbERT

1992 Les structures anthropologiques de l'imaginaire. Paris: Dunod.

Eliade, Mircea

1949 Traité d'histoire des religions. Paris: Éditions Payot.

FENG, LI

2006 Landscape and Power in Early China: The Crisis and Fall of the Western Zhou 1045-771 BC. Cambridge: Cambridge University Press.

FONG, WEN, ED.

1980 The Great Bronze Age of China: An Exhibition from the People's Republic of China. New York: The Metropolitan Museum of Art.

GuO, DA-SHUN

1995 Hongshan and related cultures, in The Archaeology of Northeast China: Beyond the Great Wall: 21-64, ed. Sarah Nelson. London: Routledge.

Joralemon, Peter David

1996 In search of the Olmec cosmos: Reconstructing the world view of Mexico's first civilization, in Olmec Art of Ancient Mexico: 51-60, ed. E. P. Benson and B. del la Fuente. Washington, D.C.: National Gallery of Art.

KeIGHTLEy, DAVID

1978 Sources of Shang History: The Oracle-Bone Inscriptions of Bronze Age China. Berkeley: University of California Press.

1989 The origins of writing in China: Scripts and cultural contexts, in The Origins of Writing: 171-202, ed. Wayne M. Senner. Lincoln: University of Nebraska Press.

Kesner, Ladislav

1991 The taotie reconsidered: Meanings and functions of Shang theriomorphic imagery. Artibus Asiae 51 (2) : 29-53.

LEGGE, JAMES, TRANS.

1872 Master Zuo's Commentaries on the Spring and Autumn Annals. The Chinese Classics, vol. 5. London: Trübner.

1885 The Sacred Books of China: The Texts of Confucianism, part 4: The Li Ki, XI-XLVI). Sacred Books of the East, vol. 28, ed. F. Max Müller. Oxford: Clarendon Press.

Lévi-Strauss, Claude

1963 Split representation in the art of Asia and America, in Structural Anthropology: 245-268, ed. Claude Lévi-Strauss. New York: Basic Books.

Li, XUEQIN

1993 Liangzhu culture and Shang dynasty taotie motif, in The Problem of Meaning in Early Chinese Ritual Bronzes: 55-65, ed. Whitfield Roderick. London: SOAS. Colloquies on Art \& Archeology in Asia No. 15.

LiN, JAMES

2000 The Immortal Stone-Chinese Jades from the Neolithic Period to the Twentieth Century. London: Scala. 
LIU, LI

2004 The Chinese Neolithic Trajectories to Early States. Cambridge: Cambridge University Press.

LiU, Li, And XingCan Chen

2002 Sociopolitical change from Neolithic to Bronze Age China, in Archaeology of Asia: 149-176, ed. Miriam T. Stark. Oxford: Blackwell Publishers.

LiU, XinRU

2010 The Silk Road in World History. Oxford: Oxford University Press.

LOEHr, MAX

1953 The bronze styles of the Anyang period (1300-1028 B.c.). Archives of the Chinese Art Society of America $7: 42-53$.

Nelson, Sarah M., ED.

1995 The Archaeology of Northeast China: Beyond the Great Wall. London: Routledge.

RamaCHANDRAN, VilayanuR

2005 A Brief Tour of Human Consciousness: From Impostor Poodles to Purple Numbers. New York: Pi Press.

RAWSON, JESSICA

1999 Western Zhou archaeology, in The Cambridge History of Ancient China: From the Origins of Civilization to 221 B.C.: 352-449, ed. Michael Loewe and Edward L. Shaughnessy. Cambridge: Cambridge University Press.

RAwSON, JesSICA, ED.

1992 The British Museum Book of Chinese Art. London: The British Museum Press.

2009 Treasures from Shanghai: Ancient Chinese Bronzes and Jades. London: The British Museum Press.

Sax, Margaret, Nigel D. Meeks, and Carol Michaelson

2007 The introduction of rotary incising wheels for working jade in China, in Scientific Research on the Sculptural Arts of Asia: Proceedings of the Forbes Symposium at the Freer Gallery of Art: 20-25, ed. J. G. Douglas, P. Jett, and J. Winter. Washington, D.C.: Archetype Publications with the Freer Gallery of Art.

Sax, Margaret, Nigel D. Meeks, Carol Michaelson, and Angela P. Middleton

2004 The identification of carving techniques on Chinese jade. Journal of Archaeological Science 31 (10) : 1413-1428.

Tang Chung, Yang Hu, and Liu Guoxiang, eds.

2007 The Origin of Jades in East Asia: Jades of the Xinglongwa Culture. Hong Kong: Centre for Chinese Archaeology and Art / The Chinese University of Hong Kong.

Teng, Shu P'ING

2000 The original significance of $b i$ disks: Insights based on Liangzhu jade $b i$ with incised symbolic motifs. Journal of East Asian Archaeology 2 (1) : 165-194.

WATKins, CalverT

1995 How to Kill a Dragon: Aspects of Indo-European Poetics. Oxford: Oxford University Press.

Wu, Lingyun, Tang Zhenquan, Jia Junshi, Cao Sui, Liu Jinshun, and Xiang Jinyan

2007 Treasures from the Museum of the Nanyue King. Beijing: Cultural Relics Publishing House.

Xiong, Chuanxin and You Zhenqun

2006 Mawangdui Han Tombs in Changsha. Hong Kong: SDX Joint Publishing Company.

ZEKI, SEMIR

1999 Inner Vision: An Exploration of Art and the Brain. Oxford: Oxford University Press.

\begin{abstract}
For decades scholars have been discussing the meaning, purpose, and function of the various styles of decoration found in jade and bronze objects produced in the period spanning the Neolithic to the Han dynasty. Max Loehr made a significant contribution to this discussion in 1953 when he made the first attempt to understand the nature and sequence of styles of bronze décor from the Anyang period (1300-1038 B.c.), which corresponds to the late Shang dynasty. Since then scholars have been divided by two different points of view. Taking one side are those who concentrate on the iconograph-
\end{abstract}


ical meaning of the figures represented on the surface of jades and bronzes, suggesting that ornaments are correlated with, and an expression of, a preexistent system of beliefs. On the other side are those who consider the nature and evolution of the sequence of designs and styles as an artistic sophistication that must be considered independently of any exterior motivation, such as a system of religious beliefs. This article aims to explore the purpose and meaning of jade and bronze decorations, particularly those representations of real and mythical animals as forms of spiritual and political empowerment. Through the examination of the nature and sequence of iconographic motifs interpreted as archetypal forms, this article demonstrates the existence of distinct moments for the meaning and purpose of jade and bronze ornaments. During the moments when spirituality and the sacred rituals are dominant and overlap political power, the use of jade and bronze objects decorated with power-animals are manifestations of a system of beliefs. On the other hand, during the moments when political power enlists spirituality and sacred rituals as instruments of sovereignty, the designs tend to be more inventive and sophisticated, corresponding to technological improvements. Consequently, iconographic motifs lose their spiritual meaning and purpose to an immanent sense of design within an artistic phenomenon. Keywords: China, bronze, jade, Shang, Zhou, iconography, animal power, archetypes. 